\title{
Coordinated Cluster and ground-based instrument observations of transient changes in the magnetopause boundary layer during an interval of predominantly northward IMF: relation to reconnection pulses and FTE signatures
}

M. Lockwood ${ }^{1,2}$, A. Fazakerley ${ }^{3}$, H. Opgenoorth ${ }^{4}$, J. Moen $^{5,6}$, A. P. van Eyken ${ }^{7}$, M. Dunlop ${ }^{14}$, J.-M. Bosqued ${ }^{8}$, G. Lu $^{9}$, C. Cully ${ }^{17}$, P. Eglitis ${ }^{4}$, I. W. McCrea ${ }^{1}$, M. A. Hapgood ${ }^{1}$, M. N. Wild ${ }^{1}$, R. Stamper ${ }^{1}$, W. Denig ${ }^{15}$, M. Taylor ${ }^{3}$, J. A. Wild ${ }^{10}$, G. Provan ${ }^{10}$, O. Amm ${ }^{11}$, K. Kauristie ${ }^{11}$, T. Pulkkinen ${ }^{11}$, A. Strømme ${ }^{12}$, P. Prikryl ${ }^{13}$, F. Pitout ${ }^{4}$, A. Balogh ${ }^{14}$, H. Rème ${ }^{8}$, R. Behlke ${ }^{4}$, T. Hansen ${ }^{12}$, R. Greenwald ${ }^{16}$, H. Frey ${ }^{21}$, S. K. Morley ${ }^{2}$, D. Alcaydéf ${ }^{8}$ P.-L. Blelly ${ }^{8}$, E. Donovan ${ }^{17}$, M. Engebretson ${ }^{18}$, M. Lester ${ }^{10}$, J. Watermann ${ }^{19}$, and M. F. Marcucci ${ }^{20}$

${ }^{1}$ Solar Terrestrial Physics Division, Department of Space Science and Technology, Rutherford Appleton Laboratory, Oxfordshire, UK

${ }^{2}$ Department of Physics and Astronomy, Southampton University, Southampton, UK

${ }^{3}$ Mullard Space Science Laboratory, Holmbury St. Mary, Surrey, UK

${ }^{4}$ IRF, Swedish Institute of Space Physics, Uppsala Division, Sweden

${ }^{5}$ Department of Physics, University of Oslo, Blindern, Oslo, Norway

${ }^{6}$ Also at Arctic Geophysics, University Courses on Svalbard, Longyearbyen, Norway

${ }^{7}$ EISCAT Scientific Association, Longyearbyen, Svalbard, Norway

${ }^{8}$ CESR, Centre d'Etude Spatiale des Rayonnements, Toulouse, France

${ }^{9}$ High Altitude Observatory, National Center for Atmospheric Research, Boulder, Colorado, USA

${ }^{10}$ Department of Physics and Astonomy, Leicester University, Leicester, UK

${ }^{11}$ Finnish Meteorological Institute, Helsinki, Finland

${ }^{12}$ University of Troms $\emptyset$, Troms $\emptyset$, Norway

${ }^{13}$ Communications Research Centre, Ottawa, Ontario, Canada

${ }^{14}$ Blackett Laboratory, Imperial College, London, UK

${ }^{15}$ AFRL, Hanscom AFB, Cambridge, MA, USA

${ }^{16}$ Remote Sensing Group, Applied Physics Laboratory, John Hopkins University, Laurel, MD, USA

${ }^{17}$ University of Calgary, Calgary, Canada

${ }^{18}$ Department of Physics, Augsburg College, Minneapolis, MN, USA

${ }^{19}$ Danish Meteorological Institute, Kobenhavn, Denmark

${ }^{20}$ Istituto di Fisica dello Spazio Interplanetario - CNR, Rome, Italy

${ }^{21}$ Space Science Centre, Berkeley, USA

Received: 27 April 2001 - Revised: 11 July 2001 - Accepted: 16 July 2001

\begin{abstract}
We study a series of transient entries into the lowlatitude boundary layer (LLBL) of all four Cluster spacecraft during an outbound pass through the mid-afternoon magnetopause $\left(\left[X_{\mathrm{GSM}}, Y_{\mathrm{GSM}}, Z_{\mathrm{GSM}}\right] \approx[2,7,9] R_{E}\right)$. The events take place during an interval of northward IMF, as seen in the data from the ACE satellite and lagged by a propagation delay of 75 min that is well-defined by two separate studies: (1) the magnetospheric variations prior to the northward turning (Lockwood et al., 2001, this issue) and (2) the field clock angle seen by Cluster after it had emerged into the magnetosheath (Opgenoorth et al., 2001, this issue). With an additional lag of $16.5 \mathrm{~min}$, the transient LLBL events cor-
\end{abstract}

Correspondence to: M. Lockwood (m.lockwood@rl.ac.uk) relate well with swings of the IMF clock angle (in GSM) to near $90^{\circ}$. Most of this additional lag is explained by groundbased observations, which reveal signatures of transient reconnection in the pre-noon sector that then take 10-15 min to propagate eastward to 15 MLT, where they are observed by Cluster. The eastward phase speed of these signatures agrees very well with the motion deduced by the cross-correlation of the signatures seen on the four Cluster spacecraft. The evidence that these events are reconnection pulses includes: transient erosion of the noon $630 \mathrm{~nm}$ (cusp/cleft) aurora to lower latitudes; transient and travelling enhancements of the flow into the polar cap, imaged by the AMIE technique; and poleward-moving events moving into the polar cap, seen by the EISCAT Svalbard Radar (ESR). A pass of the DMSP- 
F15 satellite reveals that the open field lines near noon have been opened for some time: the more recently opened field lines were found closer to dusk where the flow transient and the poleward-moving event intersected the satellite pass. The events at Cluster have ion and electron characteristics predicted and observed by Lockwood and Hapgood (1998) for a Flux Transfer Event (FTE), with allowance for magnetospheric ion reflection at Alfvénic disturbances in the magnetopause reconnection layer. Like FTEs, the events are about $1 R_{E}$ in their direction of motion and show a rise in the magnetic field strength, but unlike FTEs, in general, they show no pressure excess in their core and hence, no characteristic bipolar signature in the boundary-normal component. However, most of the events were observed when the magnetic field was southward, i.e. on the edge of the interior magnetic cusp, or when the field was parallel to the magnetic equatorial plane. Only when the satellite begins to emerge from the exterior boundary (when the field was northward), do the events start to show a pressure excess in their core and the consequent bipolar signature. We identify the events as the first observations of FTEs at middle altitudes.

Key words. Magnetospheric physics (magnetopause, cusp and boundary layers; magnetosphere-ionosphere interactions; solar wind-magnetosphere interactions)

\section{Introduction}

The low-latitude boundary layer (LLBL) is characterised by the presence of both magnetosheath and magnetospheric plasma inside the main magnetopause current sheet (Hones et al., 1972; Akasofu et al., 1973; Eastman et al., 1976; Haerendel et al., 1978; Eastman and Hones, 1979; Sonnerup, 1980; Sckopke et al., 1981; Mitchell et al., 1987; Hapgood and Bryant, 1990; Gosling et al., 1990a, b, c; Song et al., 1990; Sckopke, 1991; Traver et al., 1991; Fuselier et al., 1992; Woch and Lundin, 1993; Woch et al., 1993; Saunders, 1983; Hapgood and Lockwood, 1993, 1995; Phan et al., 1997; Savin et al., 1997; Fujimoto et al., 1998). The origin of this layer is one of the major unanswered questions in magnetospheric physics and a key unknown in this regard is the topology of the LLBL field lines: it is interesting to note that roughly half of the papers cited above interpret the LLBL in terms of closed field lines, and the other half in terms of open field lines. There are three main classes of theory of LLBL formation (see review by Sibeck et al., 1999): (1) magnetosheath plasma is injected by some process (such as wavedriven diffusion) onto closed field lines that are already populated with magnetospheric plasma (Drakou, 1994; Lotko and Sonnerup, 1995; Treumann et al., 1991, 1995; Winske et al., 1995); (2) The plasma mixture arises on newly opened field lines along which magnetosheath plasma has flowed into the magnetosphere but magnetospheric plasma has yet to escape, either due to time-of-flight considerations (Lockwood and Smith, 1993; Onsager, 1994; Lockwood, 1997a, b; Fuselier et al., 1999; Onsager and Lockwood, 1997), or ion reflec- tion at the reconnection layer Alfvén waves (Cowley, 1982; Lockwood et al., 1996) or because a magnetic bottle still exists on open field lines (Daly and Fritz, 1982; Scholer et al., 1982a; Cowley and Lewis, 1990; Lyons et al., 1994); (3) The field lines of the LLBL had been open, allowing for the magnetosheath plasma to enter, but have subsequently been reclosed by re-reconnection (Nishida, 1989; Song and Russell, 1992; Song et al., 1994; Richard et al., 1994). In both (2) and (3), gradient and curvature drift across the open-closed boundary may sometimes help to replenish magnetospheric plasma that has been lost when it flowed across the magnetopause along open field lines.

\subsection{Middle and low altitude signatures of the LLBL}

In addition to observations made at the magnetopause, data from mid- (Woch et al., 1993, 1994) and low- (Newell and Meng, 1988, 1992) altitudes have been used to discuss the LLBL. The "cleft" precipitation is often thought of as a the field-aligned projection of the LLBL (Vasyluinas, 1979; Newell and Meng, 1988; 1989, 1992, 1993, 1994a; Newell et al., 1991). However, this concept does not allow for two important considerations. First, the low-altitude observations are of particles that are within the loss cone and the magnetopause observations are of particles that are primarily outside of the lost cone. Thus, the low-altitude observations of the LLBL require that the loss cone is filled and this need not be true of the magnetopause observations. Thus, for example, the mechanism proposed by Song and Russell (1992) will not yield a low-altitude LLBL (the filling of the loss cone with magnetosheath plasma ceasing when the field lines are re-closed), unless one also invokes strong pitch angle scattering of trapped particles on the re-closed field lines into the loss cone. Second, such field-line mapping does not allow for the effects of velocity dispersion which is significant for ions in a convecting magnetosphere (Rosenbauer et al., 1975; Reiff et al., 1977). This dispersion does not allow for LLBL boundaries at high altitudes to be mapped to low altitudes whenever there is convective flow across that boundary (Lockwood and Smith, 1993). Since observations of dayside convection show flow into the polar cap throughout much of the dayside (e.g. Jorgensen et al., 1984), usually without a pronounced restriction or throat (Heelis et al., 1976), this appears to be the case for a large fraction of the dayside. The open magnetosphere model predicts that the precipitation at low altitudes evolves in its classification from "LLBL/cleft" to "cusp" to "mantle" and then to "polar cap" as the field line evolves over the magnetopause away from the reconnection site and into the tail lobe (Cowley et al., 1991; Lockwood and Smith, 1993, 1994; Onsager et al., 1993; Lockwood, 1995). This evolution is seen in full along the flow streamlines in the steady state case and thus may sometimes be seen if the satellite follows the flow streamline quite closely (Onsager et al., 1993; Lockwood et al., 1994). Thus, several authors have argued that much of the low-altitude LLBL precipitation must be on open field lines (Lockwood and Smith, 1993; Lyons et al., 1994; Moen et al., 1996; Fuselier et al., 1991, 1992, 
1999). Other authors, while accepting that this is true when reconnection is taking place, now argue that there is also a closed LLBL at low-altitudes nearer dawn and dusk (Newell and Meng, 1997). Lockwood (1997a) has shown how adopting an open topology for the LLBL solves a number of longstanding anomalies.

The idea that the low-altitude signature of the LLBL is ion open field lines is supported by the fact that it covers roughly the same longitudinal extent as the low-altitude mantle (Newell and Meng, 1992), which is known to also be on open field lines (Xu et al., 1995). The longitudinal extent of the cusp is lower than that of both the LLBL and the mantle (Aparicio et al., 1991; Newell and Meng, 1992) and would be set by the longitudinal variation of sheath plasma concentration (Lockwood, 1997a). In addition, studies of the voltage across regions of low-altitude LLBL precipitation in both hemispheres (Lu et al., 1994) show that on any one flank (dawn or dusk), the same voltage does not always appear in the two hemispheres: we interpret this as indicating that at least some of the flank low-altitude LLBL was on open field lines and not closed field lines in these cases. Some observations also show LLBL-like precipitation on sunward convecting field lines (Nishida et al., 1993; Nishida and Mukai, 1994). There is some debate as to whether these are truly LLBL field lines (Newell and Meng, 1994b) but the sunward convection can be explained in terms of the curvature force on open field lines but is inconsistent with mechanisms that transfer sheath plasma and momentum onto closed field lines.

\subsection{The open LLBL at the magnetopause}

Observations confirm the existence of an "open LLBL" (a term hereafter used for an LLBL on field lines that have an open topology) at the magnetopause. This type of LLBL is characterised by accelerated flows of magnetosheath-like ions. The evidence that they are injected and accelerated by flowing along newly-opened field lines includes: an observed dependence of the east-west flow direction on the IMF $B_{Y}$ component and hemisphere (Gosling et al., 1990a); results of tangential stress balance tests (Paschmann et al., 1979, 1986; Sonnerup et al., 1981, 1986; Johnstone et al., 1986); observations of D-shaped distribution functions of injected ions (Smith and Rodgers, 1991; Fuselier et al., 1991; Gosling et al., 1990b, c) as predicted by Cowley (1982); the observation of magnetosheath electron and ion edges inside the magnetic field rotational discontinuity (Gosling et al., 1990c); and depleted populations of trapped particles (Scholer et al., 1982a; Daly and Fritz, 1982). The observations by Fuselier et al. (1991) show that the ion distributions on both sides of the magnetopause of both magnetospheric and magnetosheath origin are as predicted by the theory of plasma mixing along open field lines. In addition, Smith and Rodgers (1991) applied the stress-balance test to show that the lowvelocity cut-off of the injected sheath population was close to the local de-Hoffman Teller frame velocity, as also predicted by the theory. Thus, at least part of the magnetopause
LLBL is formed by plasma mixing on field lines opened by magnetopause reconnection. Such processes could act for all IMF orientations, for example, a reconnection site at highlatitudes above the magnetic cusp, similar to the type studied by Gosling et al. (1991), has been seen to give rise to a dayside LLBL (Paschmann et al., 1990).

At this time we should clarify some semantic points about nomenclature. Some authors would not term an open field line region as an "LLBL" at all. Instead they would use the term "accelerated flows" or "reconnection layer", as envisaged by Levy et al. (1964), Heyn et al. (1988) and Lin and Lee (1993) and reserve the term LLBL for a layer on closed field lines. In addition, the open LLBL produced by lobe reconnection has also been referred to as an "overdraped lobe" (Crooker, 1992).

\subsection{The closed LLBL at the magnetopause}

Many researchers have discussed an LLBL on closed field lines (see review by Lotko and Sonnerup, 1995). Since the LLBL was found to generally flow faster away from the subsolar point (Haerendel et al., 1978), along with indications that it was also thinner at this point (Mitchell et al., 1987; Manuel and Samson, 1993), Eastman and Hones (1979) suggested that the LLBL was formed by the diffusion of magnetosheath plasma across the magnetopause. However, Sonnerup (1980) pointed out that the observed waves were not adequate to drive the required diffusion, a finding confirmed by later studies (Owen and Slavin, 1992; LaBelle and Treumann, 1995; Winske et al., 1995; Treumann et al., 1995). Other mechanisms have been proposed for particle injection onto a closed LLBL, but they were found to be either invalid or inadequate. For example, one proposed impulsive penetration mechanism has been demonstrated to be theoretically unsound (Owen and Cowley, 1991).

Nishida (1989) proposed a mechanism whereby reconnection may be responsible for plasma populations on a closed LLBL when the IMF points northward. He invoked highly patchy reconnection such that field lines opened at one reconnection site were re-closed a short time later elsewhere. During the time that the field line was open, magnetosheath plasma was free to flow in and magnetosphere plasma flowed out, thus releasing giving the observed plasma mixture which is trapped when the field line is closed again. More recently, Song and Russell (1992) and Song et al. (1994) proposed a similar mechanism, but used only two large-scale lobe reconnection sites poleward of the magnetic cusps. Numerical simulations by Richard et al. (1994) indicate that magnetosheath plasma may indeed move onto closed field lines in this manner during intervals of northward IMF.

\section{4 "Subsolar" reconnection during northward IMF}

Another possibility is that low-latitude reconnection may often be maintained during periods of northward IMF, as it is during southward IMF. The term "low-latitude" here means that the reconnection site is between the magnetic cusps such 
that it generates new open flux from closed flux. Studies of transpolar voltage as a function of IMF orientation show that the rate of production of such LLBL field lines must be low during northward IMF (Reiff and Luhmann, 1986; Cowley, 1984; Freeman et al., 1993; Boyle et al., 1997). Nevertheless, it may be sufficient to produce an open LLBL even during northward IMF, especially if the IMF clock angle $\theta$ IMF is not too small (typically $>45^{\circ}$ ). Evidence for this comes from electron and ion distribution functions and flows in the LLBL (Onsager and Fuselier, 1994; Fuselier et al., 1995; Chandler et al., 1999). In addition, studies of the cusp aurora during weakly northward IMF show evidence for continued low-latitude reconnection, in addition to lobe reconnection (Sandholt et al., 1996, 1998). Such reconnection during northward IMF was also deduced by Nishida et al. (1998) from tail observations made by the GEOTAIL satellite. One possibility, suggested by Anderson et al. (1997), is that the magnetosheath field is distorted and amplified in the plasma depletion layer (which is less readily eroded during northward IMF) and this allows low-latitude reconnection to continue even when the upstream IMF points northward. Recent work shows that if the IMF vector has a northward component, but lies at about $45^{\circ}$ of the magnetic equatorial plane $\left(45<\theta_{\mathrm{IMF}}<90^{\circ}\right)$, the cusp/cleft aurora bifurcates into two bands (Sandholt et al., 1996, 1998, 1999; Lockwood and Moen, 1999). The higher latitude part is consistent with the reconfiguration of "old" open flux by reconnection at the lobe magnetopause. There are two possible origins of the lower latitude band: it could be the signature of the loss cone refilling a closed northward-IMF LLBL, or it could be on newly opened field lines that are produced by continued sub-solar reconnection, despite the northward IMF component (probably at a different MLT to the lobe reconnection site). McCrea et al. (2000) observed the equatorward erosion of the lower latitude band using EISCAT radar data and this argues for the reconnection origin and an open LLBL.

Hall et al. (1991) found that the counterstreaming electrons often used to define the LLBL (for example, Takahashi et al., 1991) are present most of the time on most of the dayside magnetopause. Lockwood and Hapgood (1997, 1998) have used the ion observations and tangential stress balance tests to show that the counterstreaming is well explained as being a response of the electron gas to ion flight time effects, which is required to maintain quasi-neutrality on newly-opened field lines (Burch, 1985). The fact that these electron streams are seen during both southward and northward IMF therefore implies that reconnection is nearly always taking place somewhere on the magnetopause and is able to coat most of the boundary with newly-reconnected field lines and thus counterstreaming injected sheath electrons.

\subsection{Distinguishing of open and closed models of the LLBL}

Making the distinction between open and closed field lines from observations of the LLBL is notoriously difficult, but has usually rested on the forms of the particle distribution functions. It has been argued that particle distributions often used to classify field lines as closed, can arise simply in the open magnetosphere model. This does not necessarily mean that all of the LLBL is on open field lines, but it does imply that more of it may be than previously had been thought. In an open LLBL, the particle populations vary with time elapsed since the field line was reconnected. This means that any reconnection rate changes will result in spatial structure ("cusp ion steps") in the open LLBL and cusp (Lockwood and Hapgood, 1997, 1998). This concept has been used successfully to explain spatially structured magnetosheath ion precipitation at lower altitudes (Lockwood and Smith, 1992, 1994; Lockwood and Davis, 1996; Lockwood et al., 1998).

There is a good reason to search for a unified mechanism for a particle injection into the LLBL and a single magnetic topology within the LLBL. Hapgood and Bryant (1992) have shown that electron temperature varies in a consistent and repeatable manner with electron density throughout nearly all magnetopause crossings. Fluctuations in the time series of both quantities are produced by magnetopause motions, but these are effectively caused by the satellite moving back and forth along what is a continuous transition in the boundary rest frame. Such a transition, seen in the moments of the electron gas, could be present for almost any process that causes mixing of the magnetospheric and magnetosheath populations. What is significant, however, is that using these electron data to indicate the satellite's relative position in the LLBL (the "transition parameter") reveals coherent structure in both the ion flows and magnetic field, which are independent of the electron measurements (Hapgood and Bryant, 1992; Hapgood and Lockwood, 1993). Recently, Lockwood and Hapgood (1997) have shown that the transition parameter (the degree of electron mixing) bears a simple relationship to time-elapsed since reconnection, showing that transition parameter works because there are open field lines coating the magnetospheric surface, i.e. an open LLBL. With this being the case, the most significant point is that the transition parameter ordering is effective for nearly all passes in all parts of the LLBL, producing coherent variations through structures such as FTEs and accelerated flow events, as well as seemingly closed LLBL field lines (Hapgood and Lockwood, 1995). It is difficult to see how the smooth coherent structure could be achieved by a variety of mechanisms.

The identification of closed LLBL field lines has usually rested on two features, namely trapped magnetospheric particles and bi-directional streaming electrons.

\subsection{Trapped particles}

Trapped particles with a double loss cone pitch-angle distributions arise on closed field lines connecting both ionospheres. The particles are trapped between the mirror points in the two hemispheres. The problem with using such distributions to determine the status of a field line is that they can also exist on open field lines for a number of reasons.

First, a magnetospheric population is not lost as soon as the field line is opened. This is not only due to time-of- 
flight effects. The theory of Cowley (1982), as verified by the observations of Smith and Rodgers (1990), Fuselier et al. (1991) and Fedorov et al. (1999), predicts that of the order of one half of the population of magnetospheric ions which occur on the magnetopause on an open field line is reflected back into the magnetosphere in such a way as to conserve the pitch angle distribution. Lockwood (1997b) has shown how these reflected ions can combine with those that have yet to interact with the magnetopause to produce a population that appears as an undisturbed magnetospheric population. This would be seen on the same open field lines on which magnetosheath plasma is detected. The reflection also gives energised ions that are often seen in the LLBL and cusp (Hill and Reiff, 1977; Alem and Delcourt, 1995; Moen et al., 1996; Kremser et al., 1995; Lockwood, 1997b).

Lockwood et al. (1996) proposed that ions can be reflected in both the interior and exterior Alfvén waves (rotational discontinuities) that are found in the inflows to the reconnecting magnetopause from the magnetosphere and the magnetosheath. Since the plasma concentration is low in the magnetosphere, the interior RD propagates at a high Alfvén speed and the reflection of ions from it can give the considerable ion energisation that is sometimes found in the LLBL (Williams et al., 1987). By including this ion reflection, Lockwood and Moen (1996) and Lockwood (1997b) were able to obtain very good matches to the ion data from the LLBL presented by Moen et al. (1996) and Kremser et al. (1995), respectively.

In addition, there may be a local maximum in the magnetic field strength near the point where the field line threads the boundary and/or the bow shock, and thus, there can be magnetic bottles on open field lines (Cowley and Lewis, 1990) which maintain quasi-trapped double loss cone distributions of both ions and electrons (Scholer et al., 1982; Daly and Fritz, 1982). Another factor may be that energetic, large pitch angle ions and electrons can undergo gradient-B and curvature-B drifts onto open field lines. Such penetration of the open field line region by magnetospheric particles would be on the dawn side for electrons and on the dusk side for ions.

\subsection{Bi-directional streaming electrons}

The LLBL is also often found to contain bi-directional fieldaligned streams of electrons with energies of typically 20 $500 \mathrm{eV}$ (Ogilvie et al., 1984; Hall et al., 1991; Traver et al., 1991). Ogilvie et al. (1984) suggested that these originated from upward beams of accelerated ionospheric electrons seen at low altitudes (Sharp et al., 1980; Klumpar and Heikkila, 1992; Collin et al., 1982; Burch et al., 1983). For adiabatic, scatter free motion, accelerated ionospheric electrons produced in one hemisphere will arrive in the other ionosphere via the loss cone. Thus, unless they are scattered out of the loss cone, the ionosphere in the other hemisphere must also be a source of electrons which produce the observed counterstreaming. Thus, if the source of these streams is indeed acceleration of ionospheric electrons, their bi-directional nature would prove that they were on closed field lines.

The electron counterstreaming is often balanced (i.e. identical in the field parallel and anti-parallel directions), which is often cited as evidence for an ionospheric source and thus, for closed field lines (e.g. Traver et al., 1991). However, this calls for the two independent ionospheric sources to coincidentally have equal strengths (in terms of fluxes) and identical characteristics (in terms of distribution functions of the accelerated electrons produced). This may be unlikely, especially near the solstices when one of the sources would be in summer and the other in winter, and the ionospheric conditions are different. Savin et al. (1997) report an association of ELF waves with these electrons, raising the possibility that they are accelerated by such waves at the magnetopause. With this being the case, the electrons could be of either magnetosheath or ionospheric origin but for the latter, an additional acceleration and/or heating mechanism would be required at low altitudes for them to escape the ionosphere.

Thus, an alternative explanation of counterstreaming electrons would place them on open field lines, where the source is the magnetosheath (with slight heating at the magnetopause). The precipitating electrons would then mirror at low altitudes and return upward, giving balanced counterstreaming at all pitch angles outside the loss cone.

The AMPTE-UKS observations strongly suggest that the nature of these electron streams changes continuously as the satellite traverses the LLBL, such that the density increases and the temperature decreases as the magnetosheath is approached with the values that are almost identical to the magnetosheath located immediately adjacent to the boundary (Hall et al., 1991; Hapgood and Bryant, 1992; Lockwood and Hapgood, 1998). If this is indeed the case, it is very difficult to see how these electrons are of ionospheric origin, as it would require that the acceleration mechanism that is active on the ionospheric electrons would be able to match the electron population in the magnetosheath, such that there is no discontinuity across the last closed field line. The analysis of Lockwood and Hapgood (1997) is a very good explaination of the mixing of magnetospheric and magnetosheath electron fluxes across the boundary, and it places the counterstreaming electrons on the most recently opened field lines. With this being the case, the bi-directional streaming must arise from the presence of an injected (and slightly heated) sheath population which has travelled directly from the boundary to the satellite, as well as a population which was injected slightly earlier and has mirrored at low altitudes and returned to the satellite.

Traver et al. (1991) also report a variation in the bidirectional stream characteristics across the LLBL and observed the "hot" tail of the distribution above $200 \mathrm{eV}$. They note that LLBL fluxes are enhanced over both sheath and plasma sheet values at these energies and conclude that some electron heating is required if these are to be of sheath origin. They argued that the heating of an ionospheric source was more likely. However, recent observations of electron flows across the magnetopause by Onsager et al. (2001) show 
that such heating does indeed occur. Thus, the bi-directional electron streams can be viewed as evidence for open LLBL topology, rather than a closed one.

\subsection{The LLBL and Flux Transfer Events}

Flux transfer events (FTEs) were first identified in data taken by the ISEE 1 and 2 (Russell and Elphic, 1978, 1979) and the HEOS 2 spacecraft (Haerendel et al., 1978) at the dayside magnetopause. The key defining features of the events are a bipolar oscillation in the boundary normal component of the magnetic field $B_{N}$ and a rise in the field strength $|B|$ at the event centre. Studies using the nearby ISEE 1 and 2 spacecraft suggested that the dimension of the FTEs normal to the magnetopause was typically of the order of $1 R_{E}$ (a mean Earth radius, $1 R_{E}=6370 \mathrm{~km}$ ) (Saunders et al., 1984 $a, b)$. Statistical surveys of the occurrence of these events showed that they are seen predominantly when the magnetosheath or interplanetary magnetic field points southward (Berchem and Russell, 1984; Rijnbeek et al., 1984; Southwood et al., 1986; Kuo et al., 1995; Kawano and Russell, 1996; 1997), strongly suggesting an association with patchy and transient magnetic reconnection (Galeev et al., 1986). However, seemingly similar events observed closer to the Earth, and therefore probably deeper in the magnetosphere, show little or no tendency to occur during a southward interplanetary magnetic field (IMF) (Kawano et al., 1992; Borodkova et al., 1995; Sanny et al., 1996). Furthermore, Sibeck and Newell (1995) questioned the association of magnetospheric FTEs with southward IMF and magnetosheath field orientations, pointing out that if the sheath field was used, it was usually observed later/earlier in the same pass as the FTE and that the sheath field direction was likely to change in the intervening time. In addition, they pointed out that the spatial structure in the interplanetary medium can often result in the IMF orientation, as observed by an upstream satellite, which differs from that of the magnetosheath field, and that uncertainties in the propagation delay from the IMF monitor to the magnetopause could be important. However, none of these effects would bias the statistical surveys toward southward IMF conditions, and so they do not offer an explanation of the preponderance of the southward IMF/sheath field during FTEs.

Lockwood and Hapgood (1998) have applied the successful model of cusp ion steps (Lockwood and Smith, 1992; Lockwood and Davis, 1996; Lockwood et al., 1998) to an FTE and proved that the event was a transient entry into the open LLBL. Transient LLBL entries into the LLBL were observed by Sckopke et al. (1981), and also interpreted in terms of LLBL thickenings. However, these events were not accompanied by the classic bipolar boundary-normal field signatures that define an FTE.

The interior of FTEs is a mixture of magnetospheric and magnetosheath plasma (Thompsen et al., 1987, Farrugia et al., 1988; Lockwood and Hapgood, 1998), including energetic magnetospheric ions (Scholer et al., 1982b; Daly et al., 1984). An important feature of FTEs is that they are not equilibrium structures, i.e. there is a total pressure excess (particle plus field) in the event core (Farrugia et al., 1988; Rijnbeek et al., 1987; Lockwood and Hapgood, 1998).

The modelling of Lockwood and Hapgood (1998) confirmed that the field lines in the core of an FTE are open, as inferred from the ion composition (Thompsen et al., 1987) and ion velocity distributions (Smith and Owen, 1992). Lockwood and Hapgood also used a variant of the method by Lockwood and Smith (1992) to show that the field lines in the core of an observed event were opened in a pulse of enhanced reconnection rate. The layered structure of the event was shown to be caused by the subsequent reconnection history. Both numerical simulations and analytic theory predict that such a reconnection pulse will cause an excess (unbalanced) total pressure in the core of the event and this will then cause the open LLBL to bulge, driving a bipolar signal as the signal propagates (Scholer, 1988a, b, 1989; Semenov et al., 1991, 1995). On the other hand, Sibeck (1990) proposed that the excess pressure is not within the LLBL but in the magnetosheath, making the event a ripple of the boundary. Due to the reconnection signatures in the event core, the Sibeck theory requires ongoing reconnection, independent of the pressure enhancement. This theory provoked a great deal of discussion about whether the signatures were bulges in the reconnection layer, caused by a reconnection pulse (Southwood et al., 1988; Scholer, 1988a, b, 1989; Semenov et al., 1991, 1995), or corrugations of the reconnection layer, driven by magnetosheath pressure pulses (Sibeck, 1992; Song et al., 1994; Lockwood, 1991; Elphic, 1990). Searches for upstream pressure variations in the solar wind have failed to find events that could act as a source of the required small-scale (of the order of $1 R_{E}$ ) sheath pressure variations (Elphic and Southwood, 1987; Elphic et al., 1994).

\section{Observations}

On 14 January 2001, the four Cluster spacecraft approached the magnetopause from the tail lobe, close to the 15:00 MLT meridian. Simultaneous measurements were made using a wide array of ground-based instrumentation. An overview of this pass and of the instrumentation deployed is given by Opgenoorth et al. (2001, this issue), who also study the intersection of the exterior particle cusp by the Cluster craft at about 13:30 UT. In addition, combined Cluster and ground-based observations of polar cap patches, seen between 08:00 and 09:30 on this day, are discussed by Lockwood et al. (2001, this issue). Figure 1 presents and overview of the data recorded by Cluster and EISCAT Svalbard Radar (ESR) between 10:30 and 14:00. Figure 1a shows the plasma concentrations seen by the ESR beams pointing at low $\left(30^{\circ}\right)$ elevation along the northward magnetic meridian. Figure $1 \mathrm{~b}$ shows the plasma concentrations along the other ESR beam, aligned with the local magnetic field direction. Figure 1c shows the ions seen by the CIS instrument of the Cluster C3 spacecraft: differential energy flux is contoured in an energytime spectrogram format. Figure 1d shows the electrons seen 


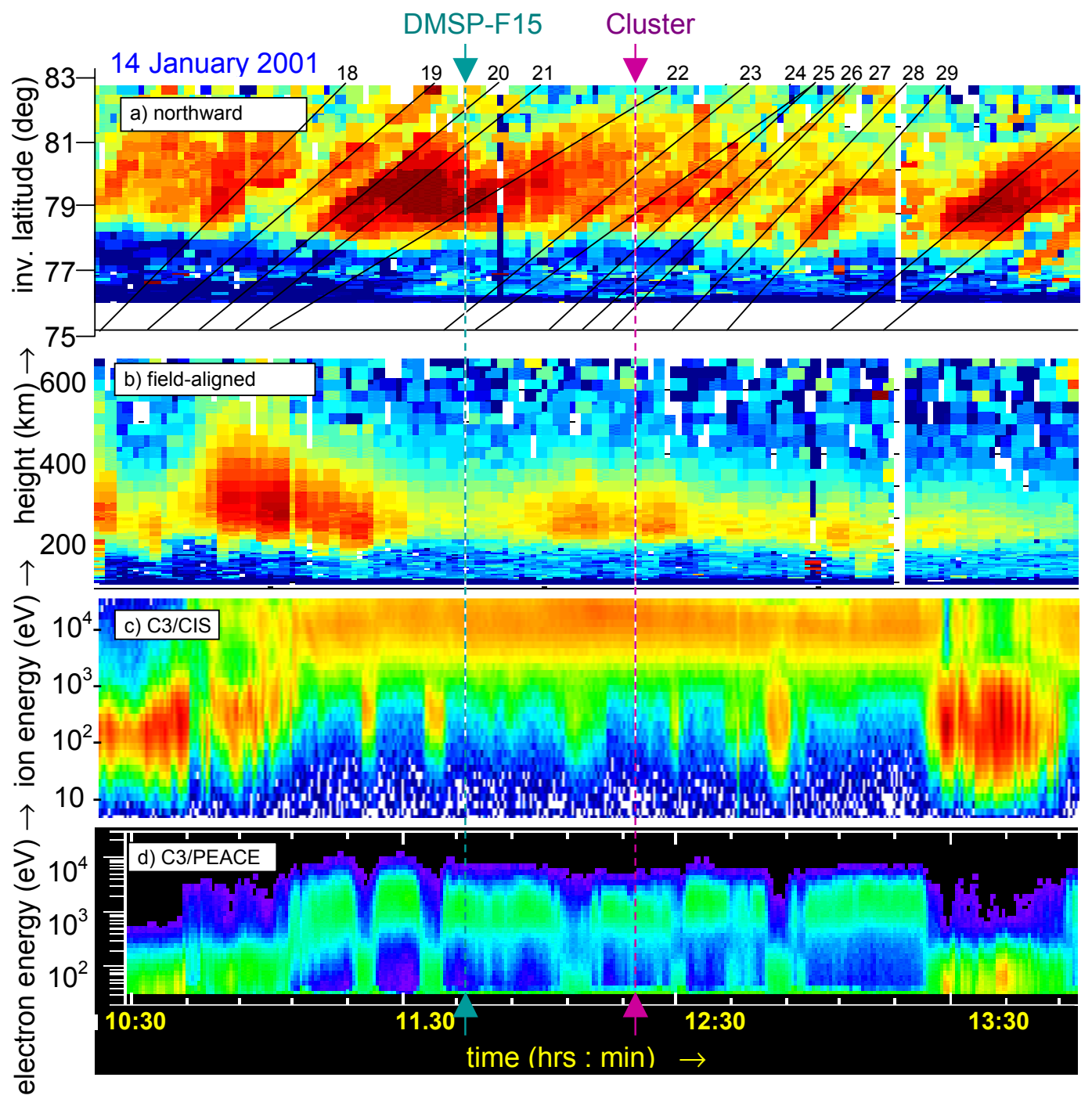

Fig. 1. Observation of transient events seen by Cluster and the EISCAT Svalbard Radar (ESR) on 14 January 2001. (a) The plasma concentrations seen in the ionosphere along the low elevation $\left(30^{\circ}\right)$ poleward beam of the ESR, are colour-coded as a function of time and latitude. The centre of poleward-moving events are marked with a black line which is numbered in continuation of the events earlier on the same day, as studied by Lockwood et al. (2001, this issue). (b) The observations along the field-aligned ESR beam are shown as a function of time and altitude. (c) An energy-time spectrogram of differential energy flux of ions, integrated over all pitch angles, as observed by the CIS instrument on Cluster C3. (d) An energy-time spectrogram of the count rate of electrons observed by the HEEA detector of the PEACE instrument on Cluster $\mathrm{C} 3$ in zone 11 (electrons moving in the $+Z_{\mathrm{GSE}}$ direction). The ESR and CIS data are colour-coded using the same scales as in Fig. 1 of Opgenoorth et al. (2001, this issue). The PEACE data are scaled using the same scale as in Fig. 8 of the present paper. The vertical dashed lines give the times of closest conjunction of the ESR and Cluster (mauve) and the ESR and the DMSP-F15 satellite (green).

in zone 11 of the HEEA detector (i.e. of electrons moving in the $+Z_{\mathrm{GSE}}$ direction) of the PEACE instrument, also on the Cluster spacecraft $\mathrm{C} 3$ : count-rates are contoured in an energy-time spectrogram format.

In this paper, we concentrate mainly on the data taken between 11:00 and 12:30 which includes close conjunctions of the ESR with the DMSP-F15 satellite and the Cluster spacecraft at about 11:44 and 12:20 UT, respectively (marked by the green and purple dashed lines in Fig. 1). In this interval, the Cluster craft were observing the dayside magnetospheric population often termed boundary plasma sheet (BPS, e.g.
Newell and Meng, 1992) with frequent, but brief, excursions into the low latitude boundary layer (LLBL). These are marked by the appearance of low-energy sheath ions and electrons (predominantly at energies below $500 \mathrm{eV}$ ) and the partial or complete disappearance of magnetospheric electrons (predominantly at energies above $500 \mathrm{eV}$ ), but not of the magnetospheric ions. Clear-cut examples of these LLBL entries are seen around 11:23, 11:37 and 12:52, with a more complex but long-lived example around 12:10. Other shortlived examples are also seen before the cusp convected eastward over the craft at around 13:30 (see Opgenoorth et al., 
2001, this issue) and further examples were seen in the interval after the cusp intersection and before the passage of the satellites through the magnetopause (not shown here, see Opgenoorth et al., 2001, this issue).

Figure 1a shows that the poleward-pointing ESR beam continued to observe poleward-moving events, as it had during the prior interval of southward IMF (see Lockwood et al., 2001, this issue). The numbering scheme used in Fig. 1 is a continuation of that used in the previous paper. However, these events were slightly less frequent and migrated poleward at a somewhat lower phase speed that they had earlier (see Fig. 8 of Lockwood et al., 2001, this issue). Another difference is that these were not, in general, seen by the field-aligned ESR beam (Fig. 1b). Blelly et al. (2001, private communication) have shown that even the event that was seen by the ESR field-aligned beam at around 11:00, does not have the same origin as the events (numbers 20, 21, and 22) seen in the northward-pointing beam. At this time the convection pattern was evolving in a complex way, following the northward turning of the IMF. Figure 2 is an overview of the magnetic field seen by the FGM instruments on the four Cluster spacecraft on this pass: the four panels give $B_{X}, B_{Y}$ and $B_{Z}$ in GSE coordinates and $|B|$. All four spacecraft show almost identical variations on the timescales shown here. At the start of the plot at 11:00 $\left[B_{X}\right]_{\mathrm{GSE}}>0$, but this reverses to $\left[B_{X}\right]_{\mathrm{GSE}}<0$ after about 12:00 combined with the plasma data (which show a progression from lobe to mantle to dayside plasma sheet), we interpret this as a motion of the spacecraft from tail-like field lines onto dayside field lines; $\left[B_{Y}\right]_{\mathrm{GSE}}<0$ is true at all times when Cluster is in the magnetosphere, which is as expected for the 15 MLT location of the spacecraft; $\left[B_{Z}\right]_{\mathrm{GSE}}<0$ until about $12: 05$, it is approximately zero for $12: 05-13: 15$, and subsequently, $\left[B_{Z}\right]_{\mathrm{GSE}}>0$ for the remainder of the time that Cluster is within the magnetosphere. Thus, Cluster was initially observing the interior boundary layers LLBL/BPS (i.e. on southward-pointing field lines in the magnetic cusp funnel, half way along the boundary field lines between the exterior magnetopause and middle altitudes). From 12:05-13:15, Cluster was observing the field lines that connect the interior and exterior, and interior boundaries $\left(B_{Z} \approx 0\right)$, and subsequently, the spacecraft observed the exterior magnetopause boundary layers $\left(B_{Z}>0\right)$ where they intersected the exterior cusp at about 13:30 (Opgenoorth et al., 2001, this issue). For the LLBL entry event around 11:23, which is studied in this paper in detail, the spacecraft are in the interior boundary layers $\left(B_{Z}<0\right)$. We also look at an event around 12:10, when the spacecraft were in the region with $B_{Z} \approx 0$ and an event around 12:53. Within this last event is a pulse of positive $B_{Z}$, and this event takes place when the spacecraft are close to the exterior boundary layers $\left(B_{Z}>0\right)$. Figure 3 of Lockwood et al. (2001, this issue) gives the interplanetary magnetic field seen by the ACE spacecraft on this day. Opgenoorth et al. (2001, this issue) report a very high cross-correlation of the clock angle of the magnetosheath field (in the GSE $Z Y$ plane) seen by Cluster, once it had emerged from the magnetosphere after 15:00 UT, with the same angle seen by
ACE. The conservation of clock angle across the bow shock reveals a lag of 74 min between ACE and the magnetosheath. Lockwood et al. (2001, this issue) have cross-correlated magnetic perturbation seen by the IMAGE magnetometer chain before the northward turning and derived a lag between ACE and the ionosphere that fluctuated around $75 \mathrm{~min}$. Given that the propagation delay from the magnetopause to the dayside auroral ionosphere is typically $1-2 \mathrm{~min}$, these lag estimates are highly consistent. In the interval studied in this paper, the lagged IMF is predominantly northward: the effects of a clear northward turning of the IMF seen by ACE around 09:50 are clearly detected around 11:00 in magnetometer deflections, and the transpolar voltage from the potential model fits to the SuperDARN radar data. Here we concentrate on the Cluster data taken in intervals marked B and C in Fig. 3 of Lockwood et al. (2001, this issue). When allowing for the derived propagation lag of $75 \mathrm{~min}$, these intervals correspond to 11:19-11:27 UT and 12:00-12:20 UT, both of which have northward IMF (for interval $\mathrm{B}, B_{Z} \approx+3 \mathrm{nT}, B_{Y} \approx+1.5 \mathrm{nT}$ in GSM coordinates, giving a clock angle $\theta_{\mathrm{IMF}} \approx 26^{\circ}$; for interval $\mathrm{C}, B_{Z} \approx+3 \mathrm{nT}, B_{Y} \approx-3 \mathrm{nT}$, giving $\theta_{\mathrm{IMF}} \approx 45^{\circ}$ ). However, both follow intervals in which the IMF $B_{Z}$ component fell briefly to near to zero $\left(\theta_{\mathrm{IMF}} \approx 90^{\circ}\right)$, with a positive IMF $B_{Y}$.

This association is stressed in Fig. 3 which shows the PEACE electron data from Fig. 1d with the IMF clock angle in GSM ( $\theta_{\mathrm{IMF}}$, Fig. $\left.3 \mathrm{~b}\right)$, and the solar wind dynamic pressure data observed by ACE $\left(P_{S W}\right.$, Fig. $\left.3 \mathrm{c}\right)$. The interplanetary data are plotted on a time scale that is lagged by the nominal delay of $75 \mathrm{~min}$, but an additional offset of $16.5 \mathrm{~min}$ has been introduced between the PEACE data and the ACE data plots, making a total lag of $91.5 \mathrm{~min}$. This lag provides a good alignment of the event seen by Cluster around 12:10, when Cluster and the ESR were in close conjunction. However, Fig. 3 also demonstrates that there is a general correspondence between the onset of other LLBL events and the increases in the IMF clock angle. There is no correspondence between the solar wind dynamic pressure changes and this or any other lag. The origin of the additional lag of $16.5 \mathrm{~min}$, however, requires an explanation before the LLBL events can be associated with the swings of the IMF vector toward the magnetospheric equatorial plane (the rises in $\theta_{\mathrm{IMF}}$ ).

\subsection{DMSP-F15 observations}

Figure 4 shows (a) the electrons and (b) the ions observed by DMSP-F15 as it passed equatorward, moving close to the ESR field-aligned beam around 11:44. The path of the satellite relative to the two ESR beams is given in Fig. 5 in invariant latitude with Magnetic Local Time ( $\Lambda$-MLT) coordinates. In Fig. 4, the differential energy flux is plotted as a function of energy (increasing upward) and observation time. The satellite entered the polar cap, passing through an auroral oval showing a series of inverted- $\mathrm{V}$ electron arcs at 11:36-11:39 UT, at around $\Lambda=70^{\circ}$ and 19:00 MLT. The purple line in Fig. 4c shows the horizontal convection velocity perpendicular to the satellite track, which changed from 


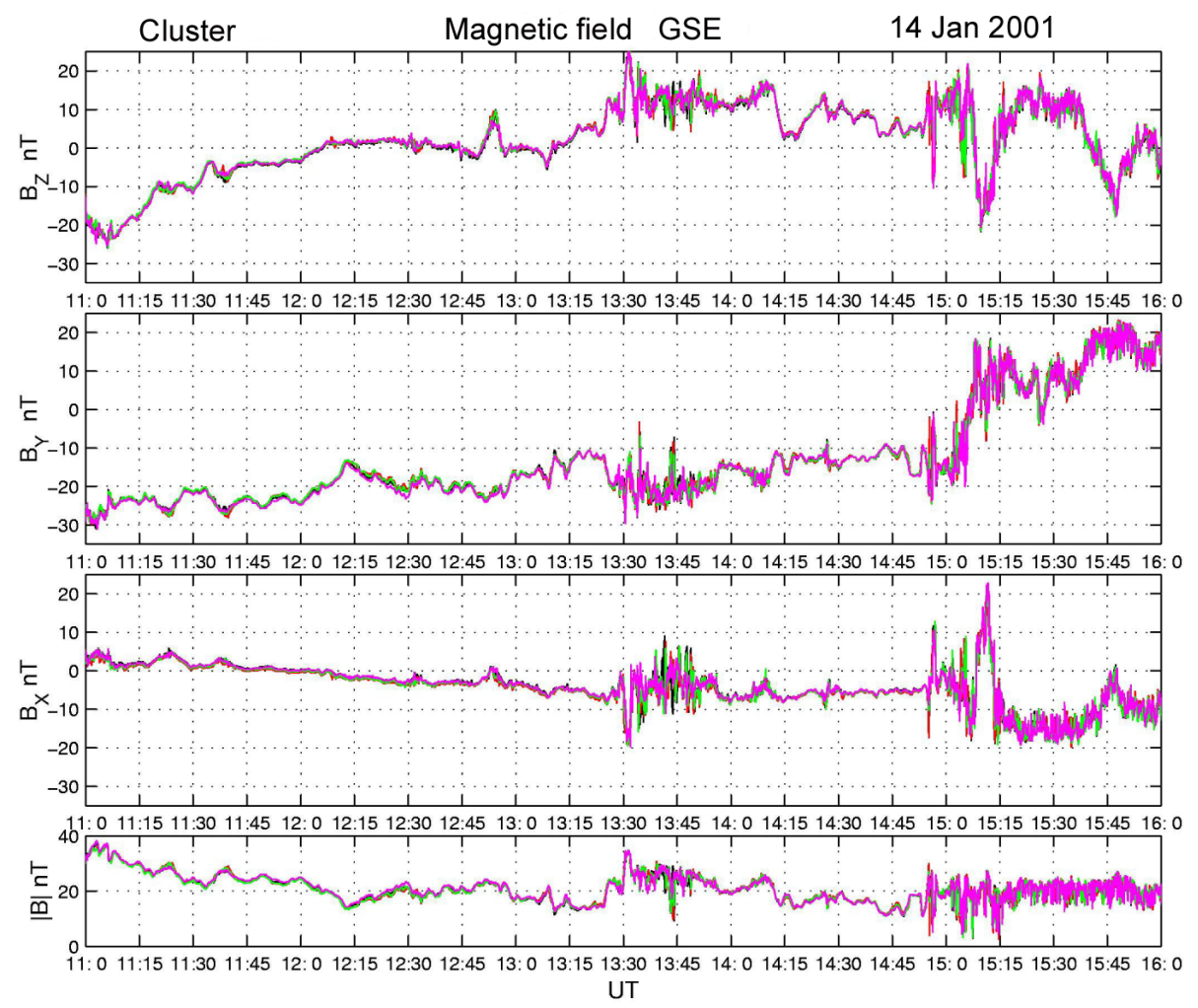

Fig. 2. The magnetic field observed by the four Cluster spacecraft at $11: 16$ UT on 14 January 2001 . The plots shows the $B_{X}, B_{Y}$ and $B_{Z}$ components in the GSE frame and the field magnitude $|B|$. Data from spacecraft C1, C2, C3 and C4 are coloured (respectively) black, red, green and magenta. (Note: in this figure, data have been plotted in the order of $\mathrm{C} 1, \mathrm{C} 2, \mathrm{C} 3$ and then $\mathrm{C} 4$ and since the data are very similar on this time scale, the magenta line for $\mathrm{C} 4$ has covered much of the other three lines).

sunward (i.e. from right to left when looking forward along the orbit) to weakly "anti-sunward" (i.e. from left to right across the orbit) close to the poleward edge of this auroral oval. The segment of the DMSP-F15 path that revealed the sunward flow channel and inverted- $\mathrm{V}$ events is marked with a thicker line in Fig. 5. At the poleward edge of the inverted- $\mathrm{V}$ events, the satellite observed a convection reversal boundary, with anti-sunward flow persisting thereafter.

The satellite was then briefly within a region where it observed polar cap precipitation, with brief intersections of magnetosheath. No significant ion flux was seen and the convection was anti-sunward. This persisted until about 11:41:30, when the satellite began to observe persistent sheath electron fluxes. This segment of the orbit is also marked with a thick line in Fig. 4, labelled sheath-like electrons because the spectrum is notably lacking in the lowest energy electrons of the sheath distribution. At this time, weak fluxes of ions are seen at about 3-20 kV. Just before the satellite's closest conjunction with the field-aligned ESR beam (at around 11:44, orange and black dashed line), the electron spectrum becomes a low-flux, low-energy sheath distribution which persists until the satellite passes through the open-closed boundary (OCB), estimated here to be at 11:45 (red and black dashed line). The OCB is identified by the disappearance of the weak sheath electron population and the onset of persistent BPS electrons. After 11:45, there is a brief dispersed electron event at low-energies and a brief drop out of the BPS electrons (at energies above about $1 \mathrm{keV}$ ). This may be a brief re-encounter with the OCB, but this is not as clear-cut as in the example presented by Lockwood et al. (2001, this issue). The OCB location is also marked on Fig. 5.

\subsection{Convection and magnetometer observations}

Figure 5 also plots the flow streamlines (equipotentials $5 \mathrm{kV}$ apart) derived by the AMIE technique for 11:40-11:45 UT, when the DMSP-F15 satellite was close to the ESR. The technique has used observations by the SuperDARN radars, ground-based magnetometers, the EISCAT radars and the DMSP satellites. The pattern shows a dominant dusk cell with only a weak dawn cell. The pattern appears to show a convection throat at high-latitudes $\left(\Lambda \approx 80-85^{\circ}\right)$ in the morning sector with eastward and poleward flow into the polar cap, suggesting negative IMF $B_{Y}$ (Heelis et al., 1976). However, the lagged IMF data at this time gives positive IMF $\mathrm{B}_{Y}$ and such an interpretation would place both the ESR beams on closed field lines, which is inconsistent with the OCB location deduced from Fig. 4. This will be discussed again below. The evolution of the pattern to the form shown in Fig. 5 is presented in Fig. 6. At 11:05, the lagged 

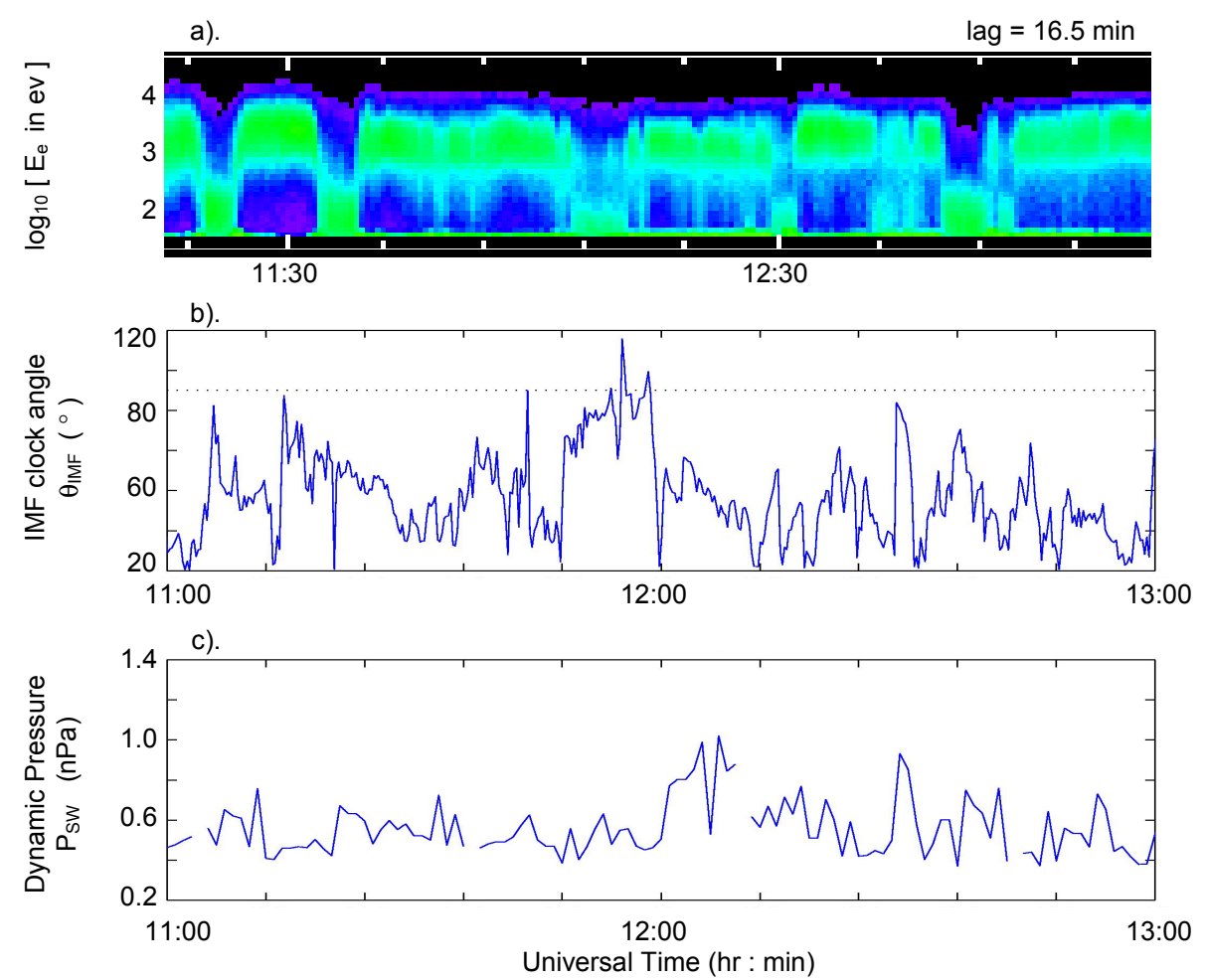

Fig. 3. (a) The PEACE data shown in Fig. 1d and compared with (b) the IMF clock angle $\theta_{\mathrm{IMF}}$ in GSM coordinates, as observed by ACE and (c) the solar wind dynamic pressure, $P_{S W}$, also observed by ACE. The ACE data are plotted against lagged time, using the nominal 75 min. lag derived independently by Lockwood et al. (2001, this issue) and Opgenoorth et al. (2001, this issue) for, respectively, before and after the period of interest in this paper. An additional lag of $16.5 \mathrm{~min}$ has been introduced to obtain a good correspondence between the transient LLBL entries seen by Cluster and the increases in $\theta_{\mathrm{IMF}}$ to near $90^{\circ}$.

IMF had turned northward, but the convection pattern had yet to respond in any significant way (the transpolar voltage is $55 \mathrm{kV}$, which was the value it had during the prior period of southward IMF, see Fig. 3, Lockwood et al., this issue), other than a small patch of low flow which appeared just to the west noon. The flow pattern had a vigorous dawn cell as well as the dominant dusk cell and the flows in the dayside polar cap were poleward and weakly westward, which is consistent with the weakly positive IMF $B_{Y}$. At 11:10, the transpolar voltage had dropped to $49 \mathrm{kV}$ and the slow flow feature evolved into an unusual distortion of the dusk cell around noon. The perturbation to the flow had additional anti-sunward flow just to the west of the ESR, with additional sunward flow to the west of that paint. By 11:15, only the additional poleward flow could be resolved, having migrated towards dusk, such that it was to the east of the ESR. The transpolar voltage had fallen to $39 \mathrm{kV}$. At 11:20, the transpolar voltage had risen again to $47 \mathrm{kV}$, primarily due to a second enhancement in poleward flow, which like the previous one, appears first near noon. The first enhancement in poleward flow can still be defined and has moved further east (but at a slower speed), occuring around 16:00 MLT at this time. After 11:25, the transpolar voltage was roughly constant at a baselevel of about $35 \mathrm{kV}$. This value is likely to reflect the rate of open flux destruction in the tail, in which case further enhancements in the dayside voltage are not going to be reflected in the transpolar voltage. It appears that poleward flow features form near noon at 11:10, 11:20 and then migrate east.

This eastward propagation may offer an explanation of some or all of the delay of $16 \mathrm{~min}$ between the IMF clock angle changes and the seemingly associated LLBL entry event. A more detailed study of the enhancements at the ESR/IMAGE meridian is presented in Fig. 7, which shows the 3 components of the lagged IMF data (by the nominal $75 \mathrm{~min}$ ), the electron data seen by PEACE-C4 (panel d), and the upward continuation of the ground $B_{X}$ perturbation, $B_{X}{ }^{\prime}$, seen by the IMAGE chain, in the same format as used by Lockwood et al. (2001, this issue). A positive $X$ (northward) component $\left(B_{X}^{\prime}>0\right)$ is a response to an eastward current. If the magnetometers are responding to a Hall current in the E-region (i.e. horizontal uniformity of conductivities can be assumed), this corresponds to a westward convection velocity in the F-region. Note that the yellow and red colours reveal positive $B_{X}{ }^{\prime}$ (eastward current and thus westward flow) whereas green and blue reveal negative $B_{X}{ }^{\prime}$ (westward current and thus eastward flow). Between 11:00 and 12:00 (roughly 14:45-15:45 MLT), westward flow was seen poleward of weaker eastward current south of the ESR; only the former of these can be seen in the AMIE flow pat- 


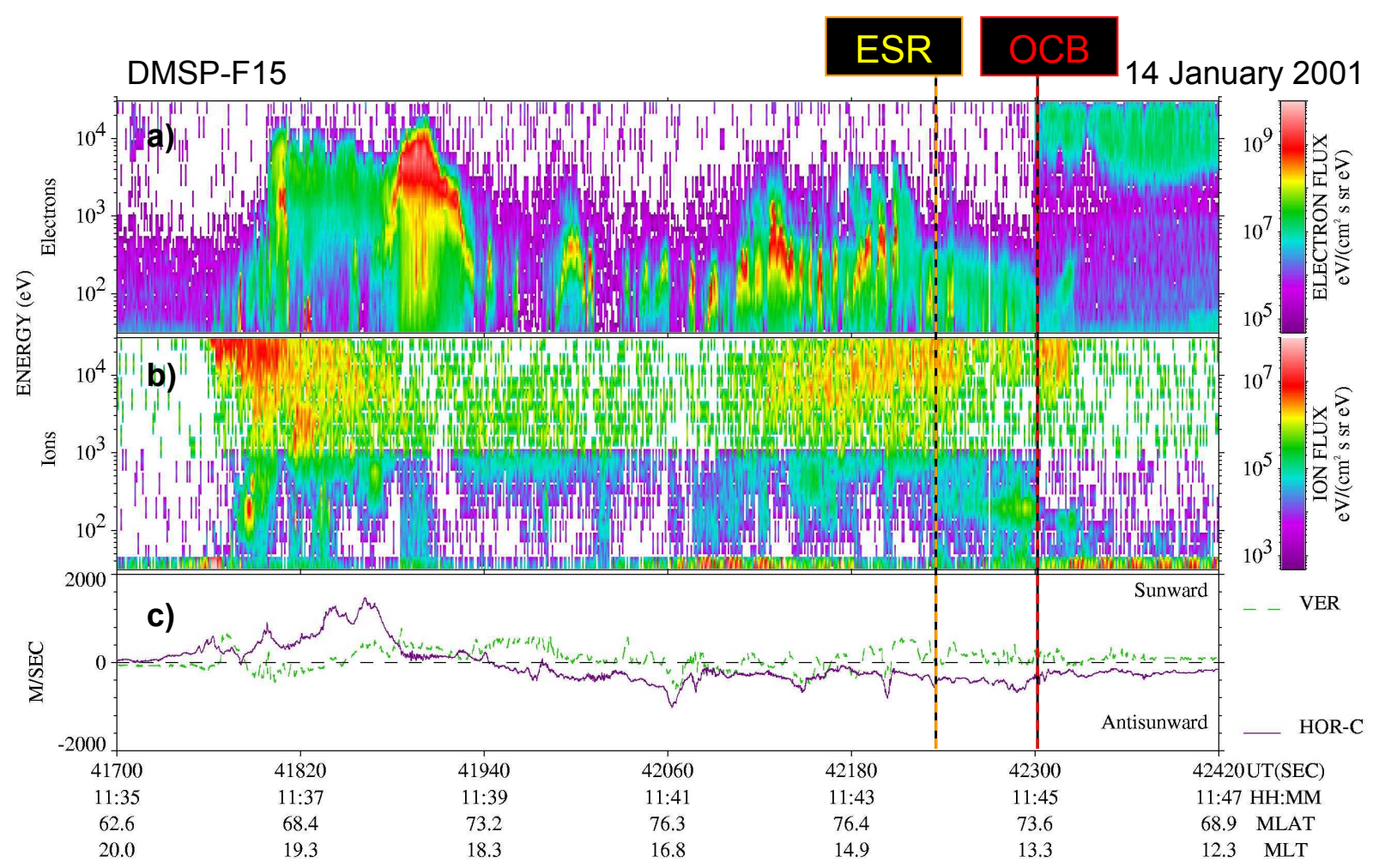

Fig. 4. Energy-time spectrograms for (a) electrons and (b) ions observed by DMSP-F15 as it passed equatorward in close conjunction with the ESR along the path shown in Fig. 5. In both cases, the differential energy flux is plotted as a function of energy (increasing upward) and observation time, $t_{s}$. (c) Shows the vertical (green) and horizontal (purple) components of the ion velocity (the horizontal component is perpendicular to the satellite track such that positive values have a sunward component and negative values have an anti-sunward component. The orange-and-black dashed line gives the time of closest conjunction with the ESR field-aligned beam and the red-and-black line gives the open-closed field line boundary (OCB) defined from the energetic magnetospheric electrons.

terns shown in Fig. 6. Figure 7e shows clear increases in $B_{X}{ }^{\prime}$ a few minutes (respectively about 7 and $5 \mathrm{~min}$ ) before the first two LLBL entry events at Cluster (at around 11:23 and 11:37 UT, Fig. 7d). Note that the first of these is clear at the highest latitudes, but is slightly masked by the (declining) residue of enhanced $B_{X}{ }^{\prime}$ due to the southward IMF prior to the northward turning. For these two events, the relevant part of the IMAGE magnetometer chain is at an MLT 49 and $35 \mathrm{~min}$ ahead of Cluster. For the third LLBL event around $12: 10$, there is an almost a coincident enhanced $B_{X}{ }^{\prime}$ event. In this third case, IMAGE is at essentially the same MLT as Cluster. These data are consistent with events propagating eastward at about $7 \mathrm{~min}$ of MLT per min (roughly $0.9 \mathrm{~km} \mathrm{~s}^{-1}$ at ionospheric altitudes), and giving both the enhanced flow signatures (detected as $B_{X}{ }^{\prime}$ increases) and a transient entry of the Cluster spacecraft into the LLBL.

If these events are also manifest as the poleward flow enhancements near noon as seen in Fig. 6 (that commence in the intervals from 11:05-11:10 and 11:15-11:20), they must have moved from noon to the IMAGE meridian at the higher average speed of $14 \mathrm{~min}$ of MLT per $1 \mathrm{~min}$ (approximately $1.8 \mathrm{~km} \mathrm{~s}^{-1}$ ) between 12 MLT and 14 MLT (double the average speed between IMAGE and Cluster at 14MLT and 15 MLT). This is consistent with the flow perturbations high- lighted in Fig. 6, as they move rapidly initially east and then they slow down. Thus, the first detected signatures of the events seen by Cluster appear to be the flow enhancements near noon at about 11:07:30 and 11:17:30 in the AMIE convection plots. These are both just $5 \mathrm{~min}$ after the transient swings of the IMF to a near $90^{\circ}$ clock angle and if one allows for the magnetopause to ionosphere propagation delay of 1-2 min, this is then within the uncertainty of the nominal lag estimate of $75 \mathrm{~min}$.

\subsection{Cluster observations}

Figures 8 to 11 present a detailed analysis of the Cluster data from the interval of 11:19 to 11:27, which includes the second of the transient LLBL events shown in Fig. 1. Table 1 gives the coordinates of the Cluster spacecraft for this interval: the $X, Y$ and $Z$ coordinates in GSM; the geocentric distance, $r$; the latitudinal and longitudinal angles, $\phi_{\mathrm{GSM}}$ and $\theta_{\mathrm{GSM}}$, respectively; the field-aligned distance to the ionosphere, $d_{i}$; and the smallest distance of the spacecraft to the model magnetopause of Shue et al. (1997), $D_{m p}$. All of these parameters are also referenced to spacecraft $\mathrm{C} 1$ so, for example $\Delta_{1} X_{\mathrm{GSM}}$ is the difference between the $X_{\mathrm{GSM}}$ of the spacecraft considered to that of spacecraft 1 . The separations 


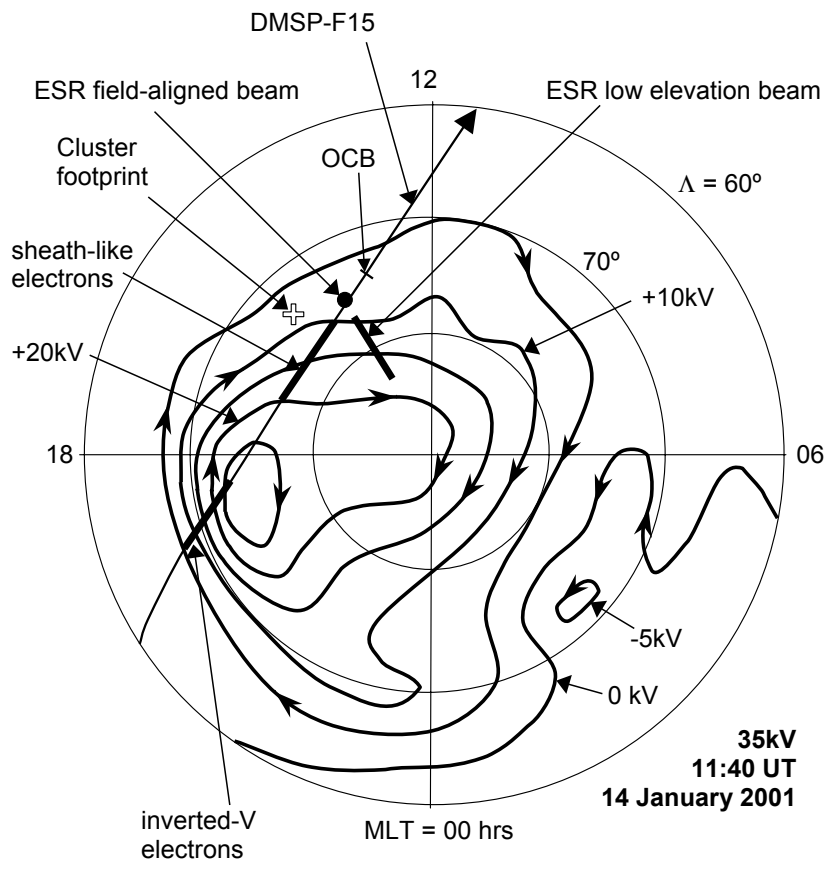

Fig. 5. An invariant-latitude $(\Delta)$ - MLT map of the convection equipotentials from the AMIE technique for magnetometer, SuperDARN, EISCAT/ESR and DMSP data post-integrated over the interval 11:40-11:45. The path of the DMSP-F15 satellite is shown, with the two thick segments showing where the satellite observed sunward convection and inverted-V electron precipitation and magnetosheath electron precipitation. The location of the open-closed boundary (OCB, crossed by DMSP-F15 at 11:45) is also marked as are the locations of the two ESR beams and the mapped footprint of the Cluster spacecraft.

are given in $\mathrm{km}$, whereas the coordinates are given in Earth radii $\left(1 R_{E}=6370 \mathrm{~km}\right)$. The separations are also given in boundary-normal coordinates $(L, M, N)$. The boundarynormal orientation was first determined from a model since the spacecraft did not intersect the magnetopause until some considerable time after the events discussed here. However, when it did intersect the magnetopause at around 15:30, the boundary-normal coordinates were found by the minimum variance technique to be almost exactly the same as those for this model. We employ the minimum variance results that give unit vectors of $(\boldsymbol{l}, \boldsymbol{m}, \boldsymbol{n})$ and $(\boldsymbol{i}, \boldsymbol{j}, \boldsymbol{k})$ in the boundary-normal and GSE frames which are related by $\boldsymbol{l}=(0.32 \boldsymbol{i}+0.59 \boldsymbol{j}-0.74 \boldsymbol{k}), \boldsymbol{m}=(0.63 \boldsymbol{i}-0.71 \boldsymbol{j}-0.29 \boldsymbol{k})$, and $\boldsymbol{n}=(0.70 \boldsymbol{i}+0.37 \boldsymbol{j}+0.61 \boldsymbol{k})$. These values are sufficiently accurate to ensure that $B_{n}$ is relatively small throughout the interval.

Table 1 shows that spacecraft $\mathrm{C} 3$ is closest to the model magnetopause (both $\Delta_{1} \mathrm{D}_{m p}$ and $\Delta_{1} \mathrm{~N}$ are maxima for this spacecraft, equal to, respectively, $+73.8 \mathrm{~km}$ and $+52.1 \mathrm{~km}$ ), whereas $\mathrm{C} 4$ is predicted to be at the deepest point in the magnetosphere (both $\Delta_{1} D_{m p}$ and $\Delta_{1} \mathrm{~N}$ are minima of $-565.2 \mathrm{~km}$ and $-467.9 \mathrm{~km}) ; \mathrm{C} 1$ and $\mathrm{C} 2$ are at a similar distance from the model boundary and $\Delta_{1} \mathrm{D}_{m p}$ and $\Delta_{1} \mathrm{~N}$ yield different answers as to which is closest: $\Delta_{1} \mathrm{D}_{m p}$ is $-13.6 \mathrm{~km}$ for $\mathrm{C} 2$,
Table 1. Cluster spacecraft coordinates and separations at 11:23 on 14 January 2001

\begin{tabular}{lcccc}
\hline & $\mathrm{C} 1$ & $\mathrm{C} 2$ & $\mathrm{C} 3$ & $\mathrm{C} 4$ \\
\hline$X_{\mathrm{GSM}}\left(R_{E}\right)$ & 1.7446 & 1.8096 & 1.7893 & 1.7282 \\
$Y_{\mathrm{GSM}}\left(R_{E}\right)$ & 7.1268 & 7.0869 & 7.1706 & 7.0970 \\
$Z_{\mathrm{GSM}}\left(R_{E}\right)$ & 8.9529 & 8.9065 & 8.8869 & 8.8689 \\
$r\left(R_{E}\right)$ & 11.5754 & 11.5250 & 11.5584 & 11.4896 \\
$\phi_{\mathrm{GSM}}\left(^{\circ}\right)$ & 50.6641 & 50.6060 & 50.2526 & 50.5255 \\
$\theta_{\mathrm{GSM}}\left({ }^{\circ}\right)$ & 76.2452 & 75.6756 & 75.9890 & 76.3138 \\
$d_{i}\left(R_{E}\right)$ & 11.1751 & 11.1282 & 11.1734 & 11.0833 \\
$D_{m p}\left(R_{E}\right)$ & -2.3993 & -2.4015 & -2.3878 & -2.4881 \\
$\Delta_{1} X_{\mathrm{GSE}}(\mathrm{km})$ & 0 & 414.6287 & 285.0409 & -103.9391 \\
$\Delta_{1} Y_{\mathrm{GSE}}(\mathrm{km})$ & 0 & -249.2815 & 286.1437 & -181.0572 \\
$\Delta_{1} Z_{\mathrm{GSE}}(\mathrm{km})$ & 0 & -299.7885 & -415.2994 & -538.0202 \\
$\Delta_{1} \mathrm{~L}(\mathrm{~km})$ & 0 & 207.4486 & 567.3594 & 258.0507 \\
$\Delta_{1} \mathrm{M}(\mathrm{km})$ & 0 & 525.1446 & 96.8506 & 219.0948 \\
$\Delta_{1} \mathrm{~N}(\mathrm{~km})$ & 0 & 15.1349 & 52.0692 & -467.9409 \\
$\Delta_{1} \mathrm{r}(\mathrm{km})$ & 0 & -321.1767 & -108.1304 & -546.2790 \\
$\Delta_{1} \phi_{\mathrm{GSM}}\left(^{\circ}\right)$ & 0 & -0.0580 & -0.4114 & -0.1386 \\
$\Delta_{1} \theta_{\mathrm{GSM}}\left(^{\circ}\right)$ & 0 & -0.5696 & -0.2562 & 0.0686 \\
$\Delta_{1} \mathrm{~d}_{i}(\mathrm{~km})$ & 0 & -298.7955 & -10.7349 & -584.4671 \\
$\Delta_{1} \mathrm{D}_{m p}(\mathrm{~km})$ & 0 & -13.5909 & 73.7636 & -565.1925 \\
\hline & & & & \\
\hline
\end{tabular}

whereas $\Delta_{1} \mathrm{~N}$ is $+15.13 \mathrm{~km}$. Figure 8 compares the electron and ion data observed by the PEACE and CIS instruments on the four spacecraft $\mathrm{C} 4$ during this interval. The top four panels show the data, from top to bottom, the HEEA detector of PEACE for spacecraft C1, C2, C3 and C4. Data are shown for zone 11, i.e. the electrons are moving in the $+Z_{\mathrm{GSE}}$ direction. This zone gives a continuous data series at the highest time resolution. The count rates (proportional to differential energy flux) are shown in spectrogram format as a function of energy and time. Also shown are data from the three functioning CIS ion instruments (on board, in order, C1, C3 and C4). The differential energy flux is shown in energy-time spectrogram format, integrated over all pitch angles. The arrows mark the appearance and disappearance of the lowest energy $(<100 \mathrm{eV})$ magnetosheath electrons in the PEACE data. They are reproduced on the CIS data panels. It can be seen that these points also mark the appearance and disappearance of the largest fluxes of magnetosheath ions. However, careful inspection reveals that there are some lower fluxes of sheath ions seen outside these two arrows, particularly by $\mathrm{C} 1$ and $\mathrm{C} 3$. Outside of the arrows, the electron data reveal both a continuously dispersed disappearance and reappearance of magnetospheric electrons and a similarly dispersed appearance and loss, respectively, of lower energy sheath electrons. This reveals that the spacecraft has passed through a layered structure, rather than witnessing a transient loss of magnetospheric electrons (for the latter, the highest energy sphere electrons would have reappeared first and the lowest energy sheath electrons would have disappeared last). This layering is consistent with the satellite passing onto open field lines along which magnetosphere electrons were lost by flowing out across the magne- 

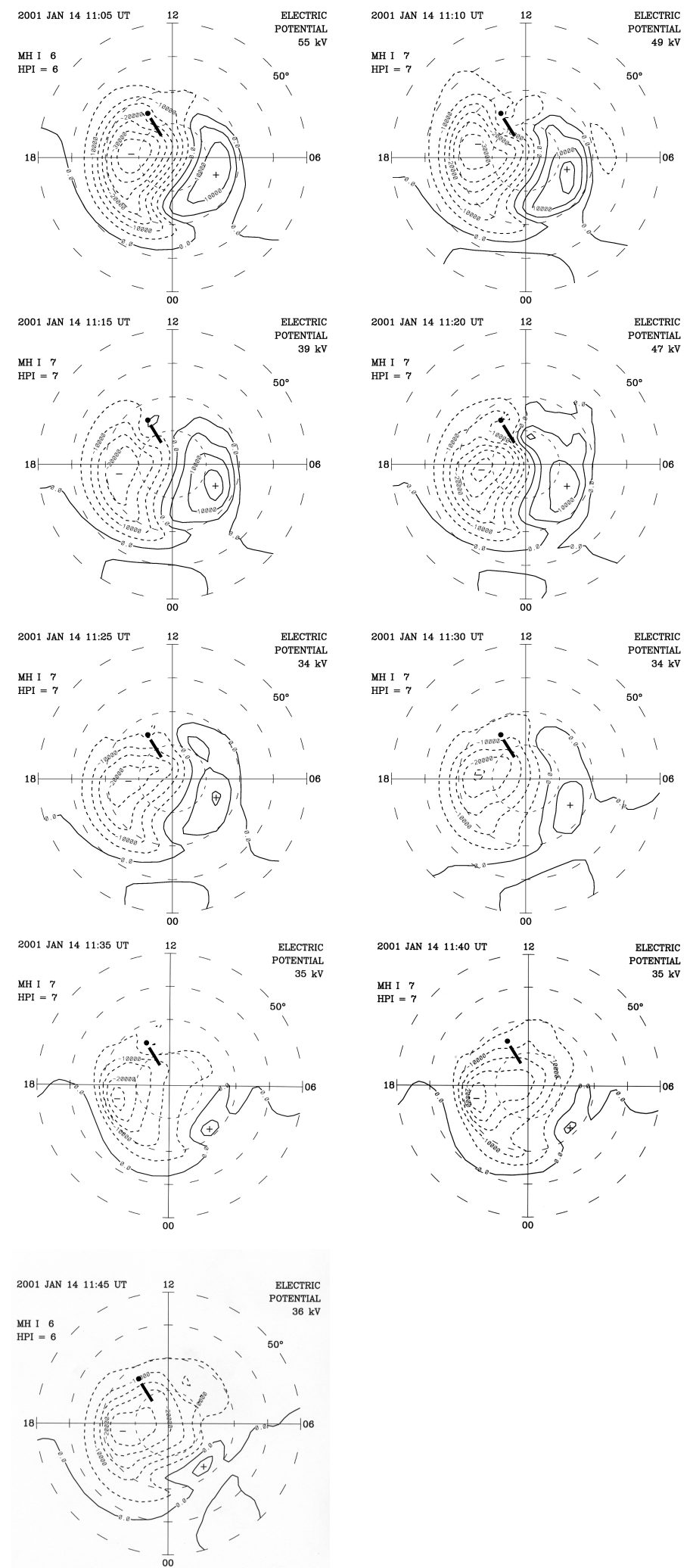

Fig. 6. The sequence of 5 min integrated AMIE convection patterns for 11:05-11:45. The locations of the two ESR beams are shown in each panel. 
a)

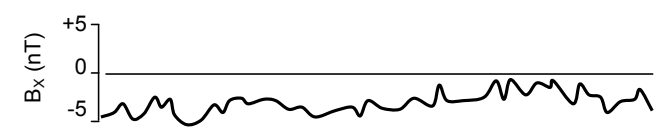

b)

c)
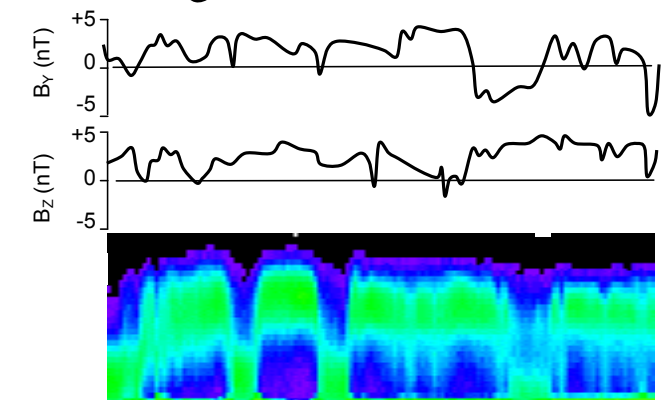

e)

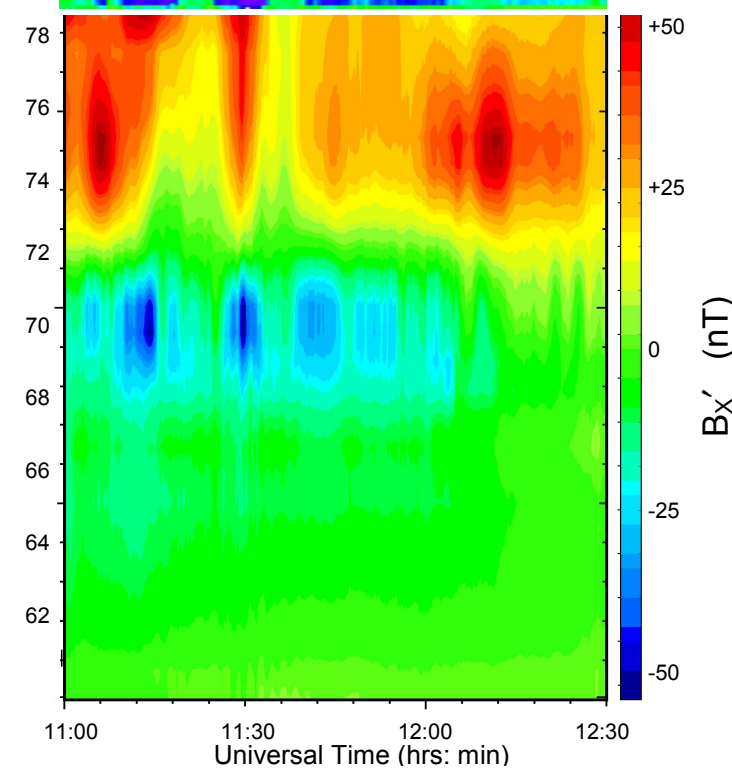

Fig. 7. (a)-(c) represent the lagged (by $75 \mathrm{~min}$ ) variations of the IMF components $B_{X}, B_{Y}$ and $B_{Z}$ in the GSM reference frame; (d) the energy-time spectrogram of the electron data seen by PEACEC4 (as shown in Figs. 1 and 3), and (e) the "upward continuation" of the $X$ component of the magnetic field $B_{X}{ }^{\prime}$ as a function of latitude and from the IMAGE magnetometer chain. The technique used to derive $B_{X}{ }^{\prime}$ employs Fourier analysis of the observations of the data from the latitudinal chain of stations on the ground to reconstruct high-resolution latitude variations that would have been observed just below the current layer.

topause, and magnetosheath electrons were gained, by flowing in the opposite direction. The time-of-flight dispersion of both reveals that the satellites passed onto field lines that had been open for longer at the event centre before returning to closed field lines. The magnetospheric ions are the apparent difficulty in this interpretation. Figure 8 shows that their flux is not really altered much at all in the event and remains constant, even when the magnetosheath ions are present. This cannot be an effect of the longer flight time of the ions (compared to electrons of the same energy) since the sheath ions have had time to arrive. Data from the RAPID instrument at higher energies confirms the decrease in flux of magnetospheric electrons but only small reductions in the flux of the ions (Wilken et al., 2001, this issue). The lack of any tran- sient decrease and recovery in the magnetosperic ions shows that their maintenance is not due to drifts onto opened then re-closed field lines. Thus, if the satellite is moving onto, and then deeper into open field lines in this event, some process is maintaining the flux of magnetospheric ions on these newly-opened field lines. The only alternative explanation is that the sheath plasma has been injected onto closed field lines, but this does not explain the loss of the magnetospheric electrons, nor the dispersion ramps outside the arrows.

Figure 9 gives the moments of the ion gas, as observed by the CIS instrument on spacecraft 4 . The times of the relevant pair of arrows in Fig. 8 are given by the two vertical lines. The panels show: (a) the proton number density, $\mathrm{N}\left(\mathrm{H}^{+}\right)$; (b) the alpha particle number density, $\mathrm{N}\left(\mathrm{He}^{++}\right)$; (c) the fieldparallel ion temperature, $\mathrm{T}_{\| \mid}$; (d) the field-perpendicular ion temperature, $\mathrm{T}_{\mid}$; and the ion velocity components; (e) $V_{X}$, (f) $V_{Y}$; and (g) $V_{Z}$, in GSE coordinates. The number density of protons and alpha particles shows the same waveform, such that the fraction of alpha particles is about $10 \%$ throughout. The mixing of the two populations means that the lower temperature sheath plasma depresses the temperatures in the event, in particular, the perpendicular temperature which falls from typical magnetospheric values of the order of $5 \times 10^{7} \mathrm{~K}$ for this location close to the dayside magnetopause to of the order of $2 \times 10^{6} \mathrm{~K}$ in the event centre which is typical of sheath values for this magnetopause location. The number densities confirm that there is additional plasma outside the event boundaries, particularly in its wake, but they have only a small effect on the average temperatures. At the event centre, the velocities are of the order of $\left[V_{X}\right]_{\mathrm{GSE}}=-20 \mathrm{~km} \mathrm{~s}^{-1},\left[V_{Y}\right]_{\mathrm{GSE}}=25 \mathrm{~km} \mathrm{~s}^{-1}$ and $\left[V_{Z}\right]_{\mathrm{GSE}}=-25 \mathrm{~km} \mathrm{~s}^{-1}$. Although these point away from noon around the magnetopause, these are much smaller values than the values seen once Cluster does emerge from the magnetopause and into the sheath, which average $\left[V_{X}, V_{Y}\right.$, $\left.V_{Z}\right]_{\mathrm{GSE}}=[-170,65,-70] \mathrm{km} \mathrm{s}^{-1}$ (see below). These characteristics clearly define the plasma as being the low-latitude boundary layer (LLBL) with a mixture of magnetospheric plasma and magnetosheath plasma, flowing anti-sunward, but at much slower speed than the sheath itself. (Mozer et al., 1994).

The spacecraft potential is measured by the EFW instrument on each spacecraft and varies with the ambient plasma concentration. Figure 10 shows the values for spacecraft $\mathrm{C} 1$ (in black), C2 (red), C3 (green) and C4 (blue). All spacecraft see the same variation, with minima outside a main central enhancement where the magnetospheric electrons are lost and magnetosheath plasma are gained, respectively. All satellites see a small secondary peak after the main peak, as can be seen in the $\mathrm{N}\left[\mathrm{H}^{+}\right]$and $\mathrm{N}\left[\mathrm{He}^{++}\right]$variations in Fig. 9. The signatures are nested to some extent, with $\mathrm{C} 4$ entering the event last and emerging from it first. Table 1 shows that $\mathrm{C} 4$ is the furthest from the nominal magnetopause location (it has the largest $\left.\left|\mathrm{D}_{m p}\right|\right)$ and thus this supports the concept of a travelling indentation of the boundary. Nesting is not so clear for the other spacecraft. The order of the observed event durations (from longest to shortest) is $\mathrm{C} 2, \mathrm{C} 3, \mathrm{C} 1, \mathrm{C} 4$; whereas 

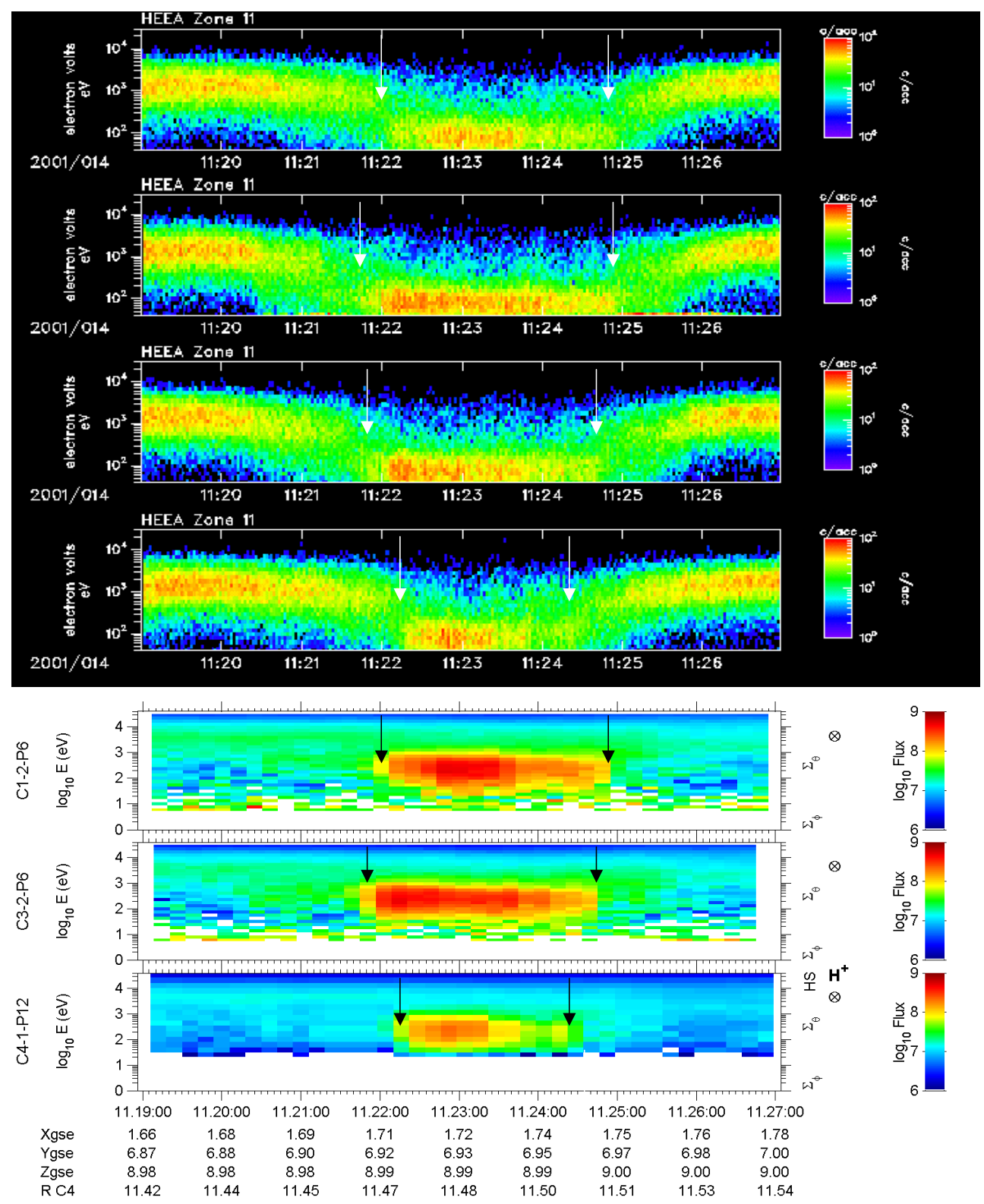

Fig. 8. Observations of the electrons and ions made by the PEACE and CIS instruments of the Cluster spacecraft at 11:19-11:27. (a)-(d) are energy-time spectrograms of count rates seen by the HEEA detector of PEACE in zone 11 (electrons moving in the $+Z_{\mathrm{GSE}}$ direction) for spacecraft C1, C2, C3 and C4, respectively. (e)-(g) are energy-time spectrograms of differential number flux observed by CIS for spacecraft $\mathrm{C} 1, \mathrm{C} 3$ and $\mathrm{C} 4$. The arrows mark the boundaries of the LLBL event, defined from the lowest energy sheath electrons, and plotted for the same times on the ion spectrograms and in Fig. 10.

the order set by a constant nested signature and the boundarynormal separations $\Delta_{1} \mathrm{~N}$ (see Table 1) would be $\mathrm{C} 3, \mathrm{C} 2, \mathrm{C} 1$, C4. The arrows in Fig. 10 are at the same times as those in Fig. 8: they are colour-coded using the same scheme as the graphs. The duration and nesting of the events defined this way are similar to those derived from the EFW spacecraft potential data.

Cross-correlating the signatures seen by EFW at the spacecraft gives a phase lag between spacecraft, which can be used to give one estimate of a phase velocity of $\left[V_{X}\right.$, $\left.V_{Y}, V_{Z}\right]_{\mathrm{GSE}}=[-24,0,9] \mathrm{km} \mathrm{s}^{-1}$, which in turn yields
$V_{\|}=1 \mathrm{~km} \mathrm{~s}^{-1}$ and $V \perp=26 \mathrm{~km} \mathrm{~s}^{-1}$ in relation to the average magnetic field direction and $\left[V_{L}, V_{M}, V_{N}\right]=$ $[-14.3,-17.7,-11.31] \mathrm{km} \mathrm{s}^{-1}$ in boundary-normal coordinates. The event is moving anti-sunward into the magnetosphere, rather than around its dusk flank. Thus, the event demonstrates a field-perpendicular convection of flux tubes, primarily moving in the anti-sunward $(-X)$ direction. Using the Tsyganenko T96 model with appropriate inputs, this velocity maps to a speed of ionosphere $V_{i} \approx 0.8 \mathrm{~km} \mathrm{~s}^{-1}$, in a direction poleward and away from noon around the afternoon sector. The core of the event at $\mathrm{C} 2$ lasts for $210 \mathrm{~s}$, 


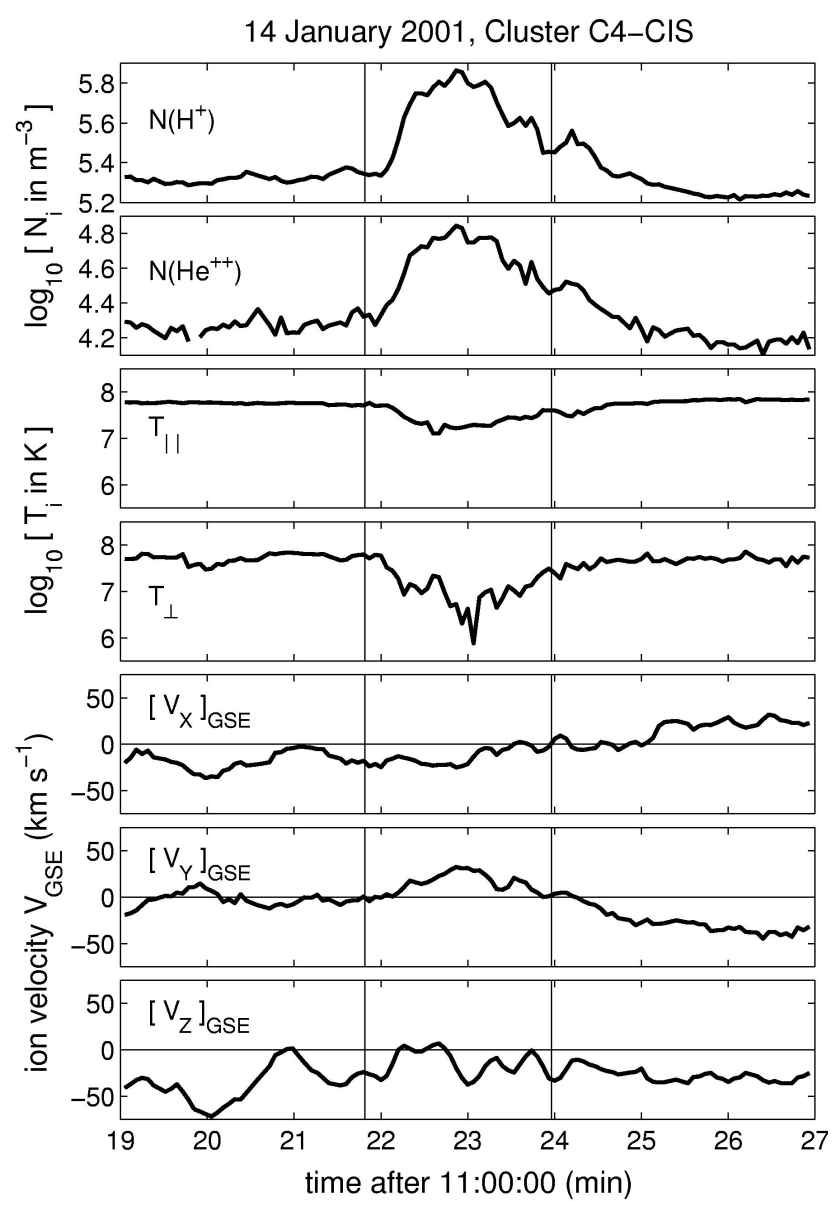

Fig. 9. The moments of the ion gas from spacecraft $\mathrm{C} 3$ for the interval shown in Fig. 8. The panels show: (a) the proton number density, $\mathrm{N}\left(\mathrm{H}^{+}\right)$; (b) the alpha particle number density, $\mathrm{N}\left(\mathrm{He}^{++}\right)$; (c) the field-parallel ion temperature, $\mathrm{T}_{\|} ;$(d) the field-perpendicular ion temperature, $\mathrm{T}_{\perp}$; and the ion velocity components (e) $V_{X}$, (f) $V_{Y}$, and (g) $V_{Z}$, in GSE coordinates.

which gives a length of structure at the magnetopause and in its direction of motion of $L \approx 26 \times 210=5460 \mathrm{~km}$ $\left(\sim 1 R_{E}\right)$, which mapped to ionosphere gives $L_{i} \approx 140 \mathrm{~km}$. Note that the average ion velocities within the event (see Fig. 9) are comparable in magnitude, but not precisely the same as the derived event phase motion. The phase motion is much lower than the exterior sheath speeds seen after the magnetopause crossing. Average velocities for $5 \mathrm{~min}$ after the satellites emerge from the sheath (i.e. for 15:0915:14 UT) are $\left[V_{X}, V_{Y}, V_{Z}\right]_{\mathrm{GSE}}=[-170,65,-70] \mathrm{km} \mathrm{s}^{-1}$, giving $\left[V_{L}, V_{M}, V_{N}\right]=[35.7,-133.0,-137.7] \mathrm{km} \mathrm{s}^{-1}$. The large negative $V_{N}$ probably indicates that the satellites are already deep into the magnetosheath for much of this time. The best alignment of sheath flow with the nominal boundary plane is seen at 15:06:10, when $\left[V_{X}, V_{Y}, V_{Z}\right]_{\mathrm{GSE}}=[-80,100,-15] \mathrm{km} \mathrm{s}^{-1}$, giving $\left[V_{L}, V_{M}, V_{N}\right]=[44.5,-117.1-28.1] \mathrm{km} \mathrm{s}^{-1}$. For either estimate, the sheath flow velocity is an order of magnitude larger than the event phase velocity. Both the event mo-

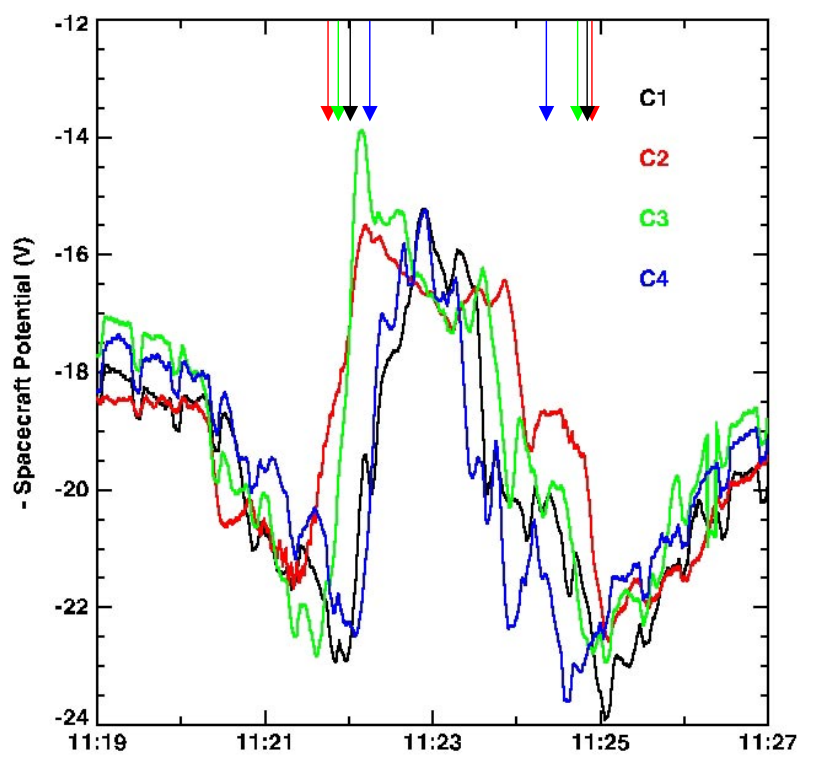

Fig. 10. The spacecraft potentials in the interval shown in Fig. 8, measured by the EFW instruments on spacecraft $\mathrm{C} 1$ (black), $\mathrm{C} 2$ (red), C3 (green) and C4 (blue). The arrows correspond to those plotted in Fig. 8.

tion and the sheath flow are towards dusk (negative $M$ component), but the event motion is equatorward (negative $L$ ), whereas the sheath flow is poleward (positive $L$ ), indicating that the magnetic curvature force, as well as the sheath flow, is playing a role in the field line evolution. The tension force must have a strong component in the $-L$ direction, implying a high-latitude reconnection site. The large differences between both the magnitude and the direction of the event velocity and the sheath velocity mean that this event is certainly not a boundary indentation caused by a feature propagating around the magnetosphere in the magnetosheath.

Figure 11 shows the magnetic field observations during this event in the boundary-normal frame, using the boundarynormal orientation discussed earlier. Fig. 11 shows no coherent signal in the boundary-normal component, $B_{N}$, and certainly no bipolar signature that could be interpreted as an FTE. However, primarily due to an increase in the $B_{M}$ component, there is a weak peak in the field magnitude, $|B|$. Thus, the event appears to be an FTE in all but one respect: it has a dimension of about $1 R_{E}$ in its direction of motion; it is moving anti-sunward into the polar cap and the motion is field-perpendicular; it contains a mixture of magnetosphere and magnetosheath plasma. The only feature lacking is the bipolar signature in the boundary-normal field.

Unfortunately, skies over Svalbard were cloudy at the time of this event and thus, we could not use auroral imagers to observe any corresponding phase motion in the mid-afternoon auroral ionosphere. However, after the skies cleared, such observations were possible for the less clear-cut event around 12:10. These are discussed in the next section. For comparison, Fig. 12 shows the PEACE and CIS data for this event, in the same format as Fig. 8. Many of the same features are ob- 


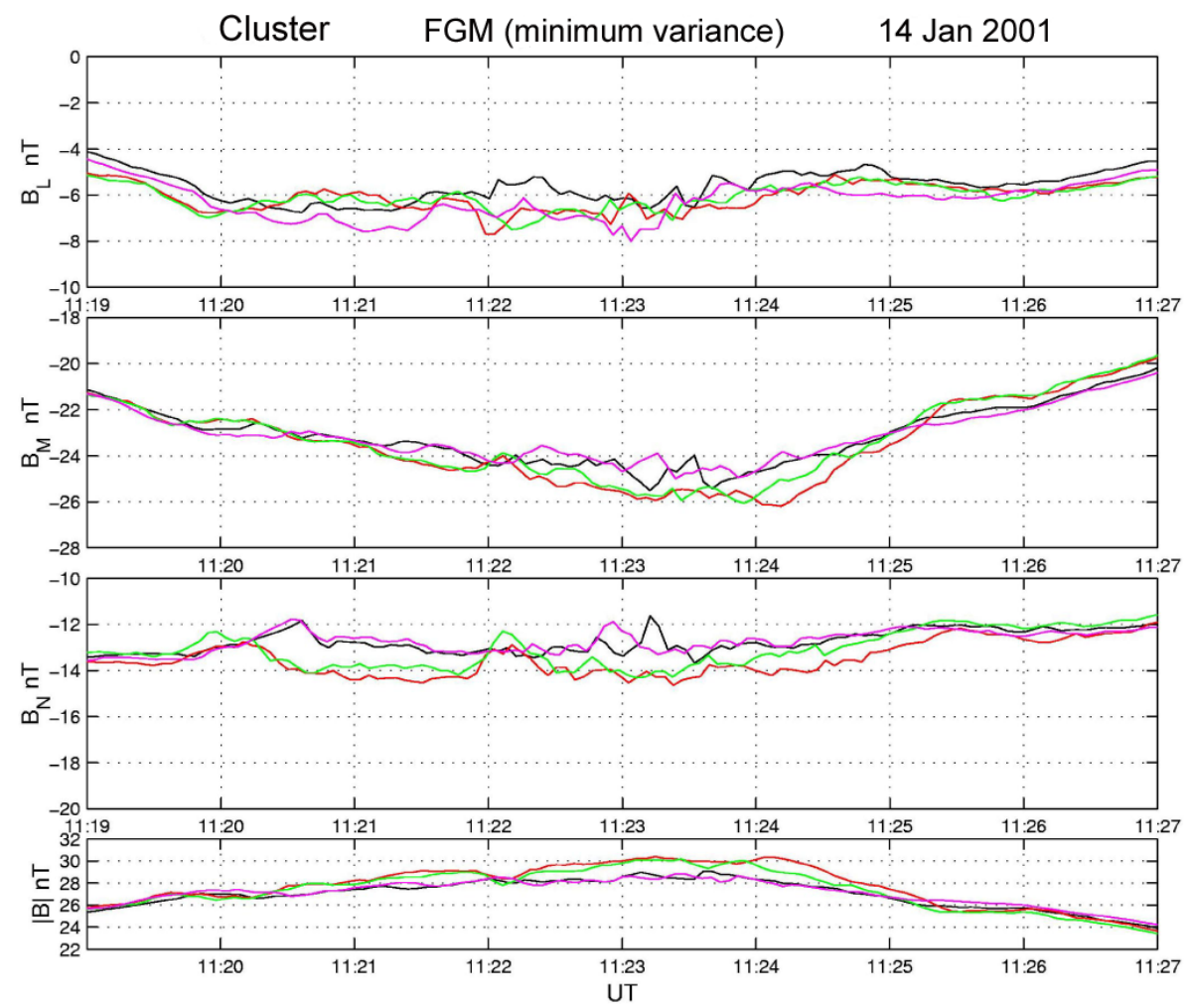

Fig. 11. The magnetic field observed by the four Cluster spacecraft during 11:19-11:27 UT on 14 January 2001. The plots shows the $B_{L}$, $B_{M}$ and $B_{N}$ components (in the boundary-normal frame described in the text) and the field magnitude $|B|$. Data from spacecraft $\mathrm{C} 1, \mathrm{C} 2, \mathrm{C} 3$ and $\mathrm{C} 4$ are coloured (respectively) black, red, green and magenta.

served, but there are also differences . The event lasts longer at all spacecraft, but sheath electron fluxes at the centre of the event are not as strong. There are more complex entries and exits from the event (in particular, for the exit from the event by $\mathrm{C} 2$ ), possibly implying corrugation and wave activity.

\subsection{Auroral observations}

Figure 13 shows a sequence of images taken at $630 \mathrm{~nm}$ by the all-sky camera at Ny Ålesund, Svalbard from 12:00-12:34. The images are in a geographic frame, with northward to the top of each image and lines of constant geographic latitude and longitude marked. Each frame also shows the outline of Svalbard, the east coast of Greenland, and the mapped footprint of Cluster as a function of time. The luminosity to the south in each frame is scattered sunlight. Frames represent $1 \mathrm{~min}$ integrations, shown every $2 \mathrm{~min}$ and the luminosity has been mapped by assuming it arises from $250 \mathrm{~km}$ altitude.

At 12:00, there was little $630 \mathrm{~nm}$ luminosity along the auroral oval: what did exist was strongest amount to the west of Svalbard near the east coast of Greenland. The MLT of the observing station at 12:00 is $\sim 4: 45 \mathrm{~h}$, and the western limb of the imager field-of-view is at an MLT of $\sim 2: 15 \mathrm{~h}$ (for an assumed emission altitude of $250 \mathrm{~km}$ ). Thus this $630 \mathrm{~nm} \mathrm{lu}-$ minosity was in the right location near noon for it to be classified as the cusp aurora. At 12:00, it was primariy to the north of the line denoting the path of the mapped Cluster footprint.
By 12:02, this noon cusp aurora had brightened and moved equatorward. Both the brightening and equatorward motion (compare its position relative to the Cluster path) continued until 12:08. This erosion is expected for enhanced reconnection, which allows for the mean radiative lifetime of the $630 \mathrm{~nm}$ emission at $110 \mathrm{~s}$ plus $1 \mathrm{~min}$ for the time-of-flight of sufficient enough ions to allow the electron precipitation flux to become sufficiently large. This means that a reconnection pulse took place near noon at about 12:00-12:05. Figure 3 shows that with the nominal lag of $75 \mathrm{~min}$, the IMF clock angle was increased in a pulse (during which it rose above $90^{\circ}$ ) between 11:54-12:00. Thus, this feature appears to be a response to the southward turning of the IMF seen by ACE, but with a lag that is about 5 min longer than the nominal value of $75 \mathrm{~min}$. This is certainly within both the uncertainty and the fluctuation level of the lag estimates.

At subsequent times (12:08-12:18), the enhanced aurora spread eastward towards Svalbard. The appearance of a rayed feature to the east of Svalbard after about 12:14 marks its arrival at the zenith of the instrument. Note that this feature is almost certainly exaggerated in size and subsequent images, since the emission comes from a wide range of altitudes and not just the $250 \mathrm{~km}$ (which is near the peak of the volume emission rate) that had been assumed. Given that enhanced luminosity first appears about $2 \mathrm{~h}$ of MLT to the west of Svalbard at 12:02, this is an approximate average 

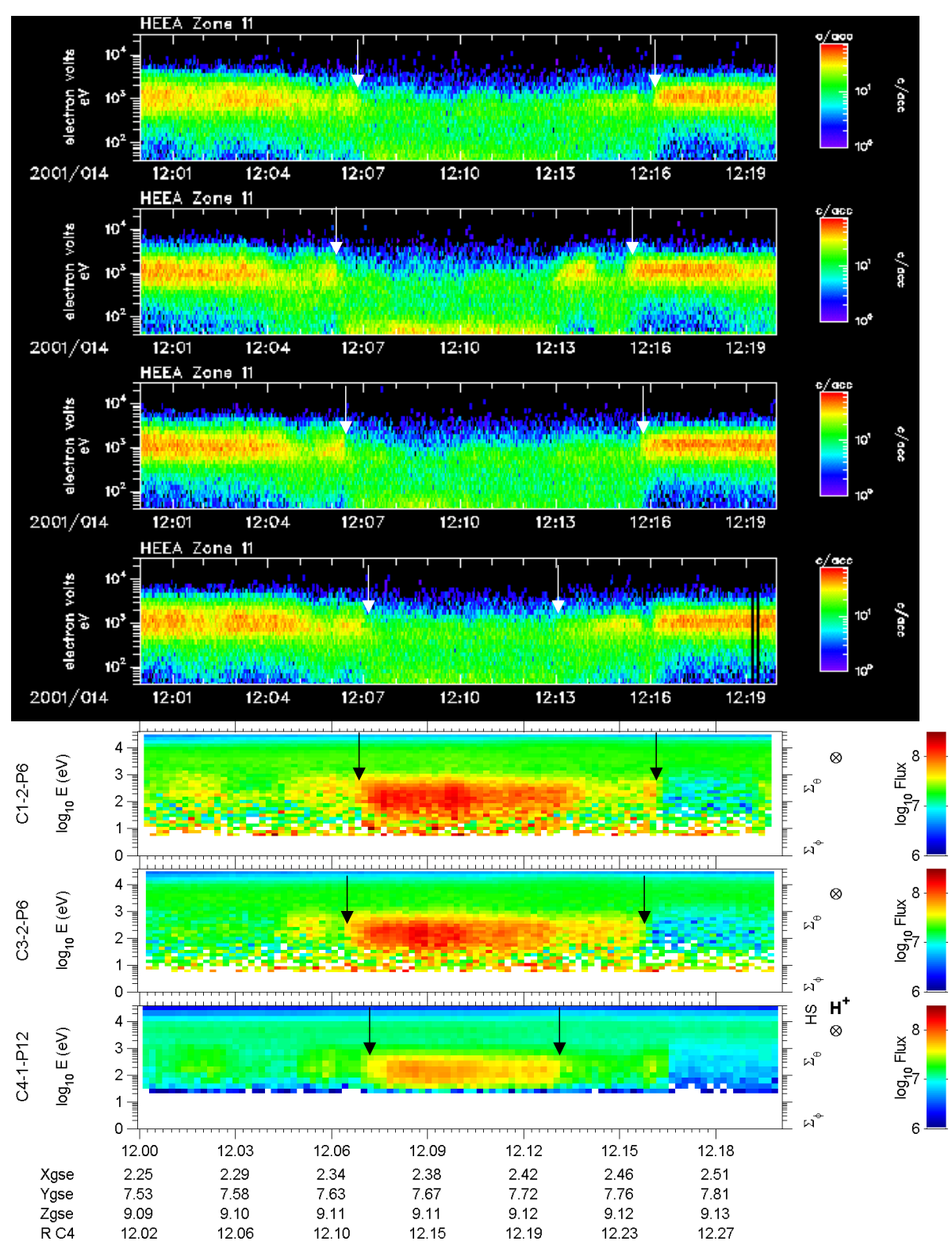

Fig. 12. Same as Fig. 8 for the interval 12:00-12:20 UT.

propagation speed of $10 \mathrm{~min}$ of MLT per min (corresponding to an ionospheric phase speed of $1.3 \mathrm{~km} \mathrm{~s}^{-1}$, very similar to the initial eastward expansion speeds inferred from the multiinstrument study of the event around 11:23). At subsequent times, the cusp aurora continues to brighten and careful inspection reveals fine structure, with a series of events propagating poleward and expanding to the east.

Figure 12 shows that the arrival of sheath electrons in the Cluster LLBL intersection began at about 12:07 which, if one allows for the particle propagation delay and the radiative lifetime, corresponds to the image at about 12:10. This is about $4 \mathrm{~min}$ before the expanding $630 \mathrm{~nm}$ aurora reached Svalbard and the Cluster footprint. Given the uncertainties of the field line mapping, it is more than possible that the event seen by Cluster is related to the eastward-expanding $630 \mathrm{~nm}$ event. Note that the expansion from first onset at 12:02 to the MLT of the ESR and Cluster (at about 12:14) explains much of the additional $16.5 \mathrm{~min}$ lag required to relate the Cluster LLBL entries and the clock angle changes in Fig. 3.

2.5 Cluster magnetometer observations of an event in the exterior boundary layer

Figure 1 shows that the series of LLBL intersections persists up to the cusp intersection at 13:30, and a particularly clearcut particle event is seen around 12:53. Figure 14 shows 


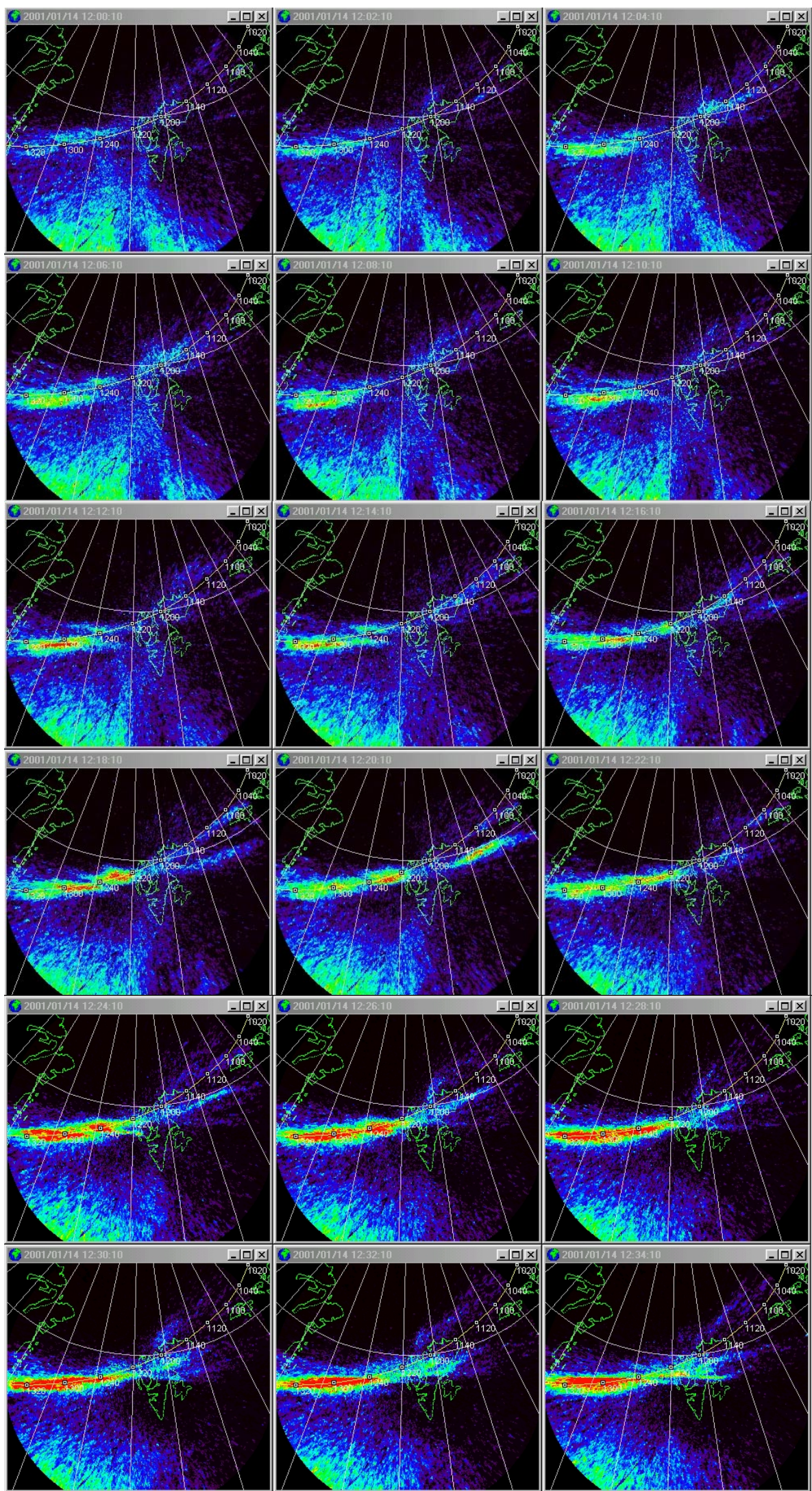

Fig. 13. One-minute integrations (shown every $2 \mathrm{~min}$ ) of $630 \mathrm{~nm}$ emissions seen by the Norwegian all-sky camera at Ny Ålesund, Svalbard. Each frame shows the outline of Svalbard and, the east coast of Greenland and lines of constant geographic latitude and longitude, and the mapped footprint of the Cluster spacecraft. All emissions have been mapped assuming an emission altitude of $250 \mathrm{~km}$. The images are ordered from left to right in each row and rows are ordered from top to bottom. The first image (top left) is for 12:00 and the last (bottom right) is for 12:34 UT. 


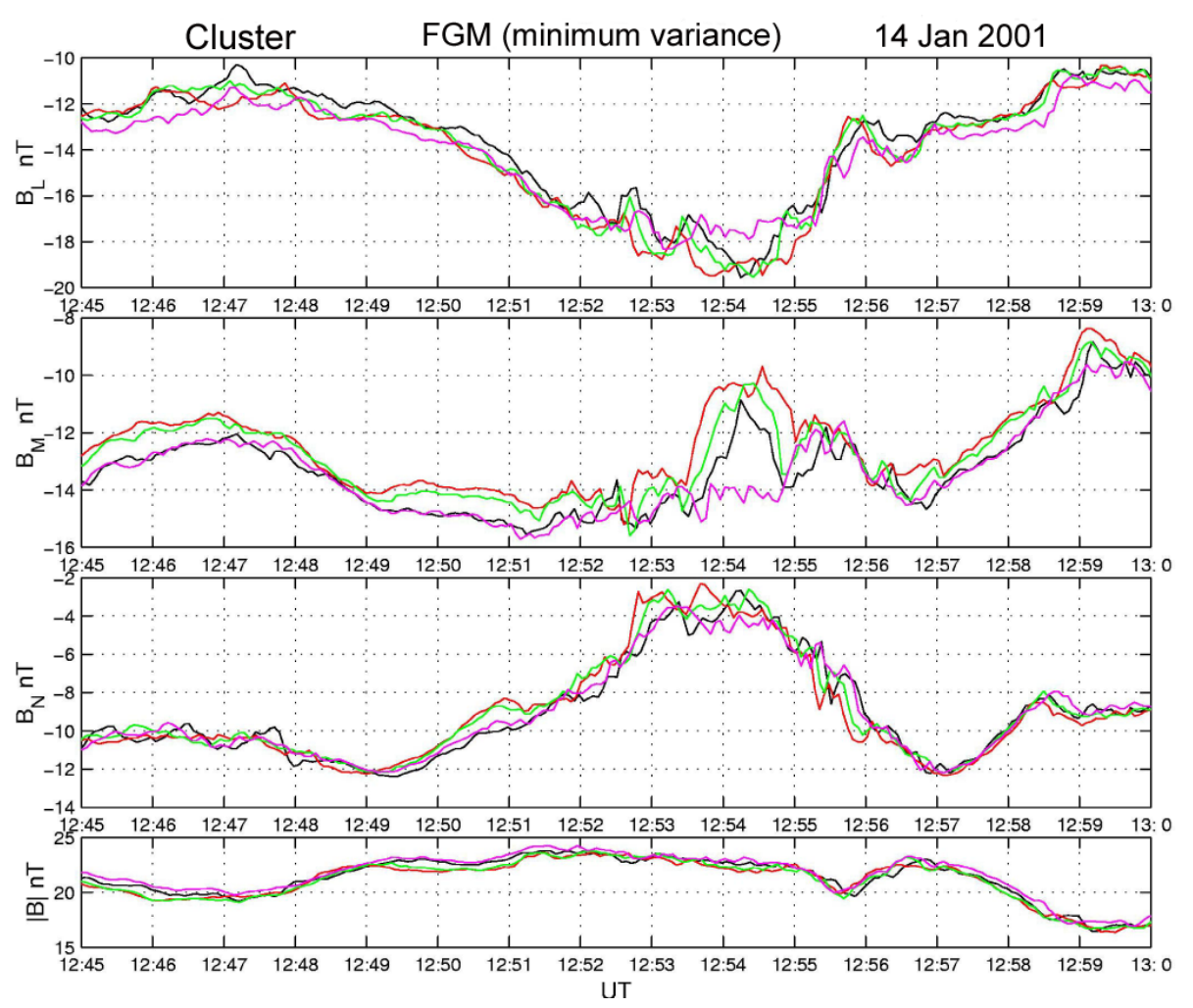

Fig. 14. The same as Fig. 11, for the interval 12:45-13:00 UT.

the magnetometer data from the four spacecraft at this time, when Cluster was close to emerging into the exterior boundary layers. A signature begins to emerge for this event, whereas the interior boundary layer events show no clear magnetic signature (Fig. 11). Figure 14 shows that this event displays a clear enhancement of the negative $B_{L}$ in boundarynormal coordinates; 3 of the 4 spacecraft show a reduction in the magnitude of the negative $B_{M}$ and there is a signature in the boundary normal field $B_{N}$ seen by all spacecraft. The magnitude of the field $|B|$ is increased in a broad peak.

In fact, careful inspection of both the electron and ion data in this event reveals that it was a double event (Fig. 1) and this is also seen in Fig. 14 which shows peaks in $\left|B_{L}\right|$ and $|B|$. In addition, the $B_{N}$ data reveal two bipolar signatures (with first $\Delta B_{N}$ negative, then positive) centred at 12:52 and 12:58. Outside the events, the field is pointing towards dawn and sunward $\left(\left[B_{X}\right]_{\mathrm{GSE}} \approx-3 \mathrm{nT},\left[B_{X}\right]_{\mathrm{GSE}} \approx-20 \mathrm{nT}\right.$, $\left[B_{Z}\right]_{\mathrm{GSE}} \approx 0$ ), so that the negative/positive polarity signal is consistent with two bumps in the magnetopause propagating anti-sunward and eastward over the spacecraft. These signatures are thus a pair of FTEs.

\section{Discussion and conclusions}

When approaching the magnetopause on an outbound pass on 14 January 2001, Cluster underwent a series of brief intersections with the Low-Latitude Boundary Layer (LLBL), both before and after it intersected the cusp at about 13:30
(Opgenoorth et al., 2001, this issue). These are similar events to those observed by INTERBALL, as reported by Savin et al. (1997), and by GEOTAIL, as reported by Fujimoto et al. (1998) but are here observed by the four Cluster spacecraft.

The dispersed disappearance and reappearance of magnetospheric electrons on the edges of these events is consistent with the satellite moving into an open LLBL, as is the appearance of sheath ions. This electron dispersion was also seen in the FTE event studied by Farrugia et al. (1988) and modelled by Lockwood and Hapgood (1998). However, that event also showed continuous dispersion of ions. The steplike edges of the injected ion events reported here is also consistent with this model, provided the reconnection is pulsed and falls to zero between the pulses (Lockwood and Davis, 1996). The two main difficulties with this interpretation are: (1) the maintenance of magnetospheric ions (but not electrons) on the open field lines and (2) the slow convection velocities of the flux tubes. Considering the former, Fig. 1c shows that some events display slight decreases in magnetospheric ion fluxes; this is the clearest for the event around 12:52. The theory of Cowley (1982) and modelling by Lockwood (1997b) offers an explanation in terms of ions which are accelerated from the reflection off of the Alfvénic disturbances in the reconnection layer (open LLBL), in particular, the external RD (Alfvén wave), the magnetopause, and the faster internal RD. Lockwood and Moen (1996) have used ion reflection off the Alfvén waves at an open magnetopause 
to match the partial moments of LLBL and cusp ions, and Lockwood (1997a) was able to reproduce the full spin angle distributions. Lockwood and Hapgood (1998) used the theory to match the moments and distributions of the ions seen within an FTE. Because there is no transient loss and then recovery of magnetospheric ions at the start of the events, there is no reason to invoke re-closure of opened field lines.

The remaining difficulty is that the field lines are moving at a velocity that is an order of magnitude slower than the sheath flow, which has been used as evidence for a closed topology (Fujimoto et al., 1998). The presence of subAlfvénic ions and electrons means that the field line motion would have responded to the opening of the field lines. Thus, for these field lines to be open, we must conclude that the tension force is counteracting the effect of the sheath flow on the part of the field line that is outside the magnetopause, such that the field lines are hung up on the dusk flank of the magnetosphere.

Table 2 summarises the evidence concerning the key questions of the magnetic topology of the field lines within the transient LLBL events. It can be seen that there are problems with either explanation. However, possibilities exist for explaining all features for an open topology (or with opened and then re-closed), and this is not the case for a closed topology.

The magnetic field measured by FGM in both the magnetosheath and the boundary layer was of the order of $20 \mathrm{nT}$, but the plasma density seen by CIS was of the order of, respectively, $10^{7} \mathrm{~m}^{-3}$ and $2 \times 10^{5} \mathrm{~m}^{-3}$. Using the mean ion mass of $1.3 \mathrm{amu}$ seen by CIS on both sides of the boundary $(10 \%$ $\mathrm{He}^{++}$and $90 \% \mathrm{H}^{+}$), we find that the exterior and interior magnetopause Alfvén waves propagated at a speed $V_{A}$ of the order of $120 \mathrm{~km} \mathrm{~s}^{-1}$ and $850 \mathrm{~km} \mathrm{~s}^{-1}$, respectively. Reflection off of these waves gives an acceleration of ions by up to $2 V_{A}$ (Cowley, 1982; Lockwood et al., 1996), which means the peak of the distribution function is shifted to $470 \mathrm{eV}$ for protons $\left(1.88 \mathrm{keV}\right.$ for $\left.\mathrm{He}^{++}\right)$for the exterior wave and $23.5 \mathrm{keV}$ $\left(0.94 \mathrm{MeV}\right.$ for $\left.\mathrm{He}^{++}\right)$for the interior wave. Considering the hot tail of the initial field-parallel magnetospheric distribution, it can be seen that reflection of the interior wave will readily generate $\mathrm{MeV}$ ions in the LLBL and cusp on open field lines, as well as maintaining fluxes of unaccelerated magnetospheric ions on open field lines (Lockwood, 1997b).

Comparison of the CIS and PEACE spectrograms at the onset of the intersection with the cusp event (13:22-13:27) is identical to the onset of one of the clear-cut events shown in this paper (e.g. 11:18-11:23). The same is true for the (somewhat protracted) exit from the cusp event. The difference appears to be that in the cusp event, the satellite moves onto field lines that have been open long enough for all magnetospheric electrons to vanish and for the low energy ion electron fluxes to rise to about half of the values in the local magnetosheath. Thus, we conclude that the cusp intersection event studied by Opgenoorth et al. (2001, this issue) is exactly the same, in principle, as the events studied here, i.e. newly-opened flux was formed by reconnection in the morning sector and dragged eastward to the satellites in all cases. The only difference is that more open flux was formed in the cusp event than in these LLBL events and they convected further over the Cluster spacecraft so that they sampled field lines of greater elapsed time since reconnection. In the cusp event, as in the LLBL events presented here, an additional propagation lag was required to match the IMF clock angle variations to the event. As for the events studied here, ground-based data reveal that the lag was due to event formation in the pre-noon sector and propagation to the midafternoon location of the spacecraft.

The events take place during predominantly northward IMF and appear to be triggered by swings of the IMF towards the ecliptic so that the IMF clock angle approaches $90^{\circ}$ in GSM coordinates. However, the lag is 15-20 min longer than observed both before and after the period of interest here. The ground-based observations explain this additional delay because signatures in both the flows and in the $630 \mathrm{~nm}$ aurora indicate that the events form in the pre-noon sector and most of the additional delay is the time taken for the events to propagate eastward to the mid-afternoon sector. The speed of the eastward phase motion seen by the ground-based instruments (of the order of $1 \mathrm{~km} \mathrm{~s}^{-1}$ ) is consistent with the phase motion of the event derived from multi-spacecraft studies using Cluster. The propagation of active segments of reconnection $X$-lines away from noon was first inferred from EISCAT radar data by Lockwood et al. (1993) and sketched schematically by Lockwood (1994). Lockwood et al. (1995) used this concept to show that FTEs can be responsible for the full transpolar voltage. Recently, Milan et al. (2000) has found further evidence for this concept in HF coherent radar data and UV global images: it has also been used to explain multiinstrument and multi-point data by McWilliams et al. (2001).

The occurrence of these events is consistent with the idea that "subsolar" reconnection (meaning the production of open field lines by the merging of closed field lines and draped interplanetary field lines, which may take place away from the equatorial plane) persists when the IMF is northward, at least as long as the IMF clock angle is greater than about $45^{\circ}$. The direction of motion of the event is in the $-L$ direction (equatorward), whereas the local sheath flow is in the $+L$ direction, suggesting the magnetic curvature force has an equatorward component and that the reconnection site responsible for the reconnection pulse was at high-latitudes.

The ESR observed poleward-moving events which are also thought to be reconnection pulse signatures. The lower occurrence rate of events, compared to the earlier interval of southward IMF (Lockwood et al., 2001, this issue) is consistent with the triggering of the northward IMF events by swings of the IMF to a greater clock angle. The events were not, in general, seen by the field-aligned ESR beam. For much of the period, this may be due to the fact that the beam was equatorward of the open-closed boundary. However, this was not the case during the pass of the DMSP-F15 satellite just after one of the events and not long after the northward turning. This revealed the ESR field-aligned beam to be on open field lines. However, these were "old" open field lines for which the magnetopause threading point was located a 
Table 2. Summary of explanations of observed features of the LLBL events

\begin{tabular}{|c|c|c|}
\hline Feature & Explanation for a closed topology & Explanation for an open topology \\
\hline 1. Appearance of magnetosheath ions & No viable mechanism known & $\begin{array}{l}\text { Well explained as ions flowing out } \\
\text { along open field lines }\end{array}$ \\
\hline 2. Loss of magnetospheric electrons & $\begin{array}{l}\text { Mechanism also unknown, but must act on } \\
\text { opposite side of magnetopause to the } \\
\text { mechanism invoked to explain } 1 \text {, yet be } \\
\text { active at the same time and place }\end{array}$ & $\begin{array}{l}\text { Well explained as electrons flowing out } \\
\text { along open field lines }\end{array}$ \\
\hline 3. Sharp edges to sheath ion regions & Not known & Requires reconnection pulses \\
\hline 4. Dispersed loss of electrons & Not known & $\begin{array}{l}\text { Well explained by time-of-flight of } \\
\text { escaping electrons }\end{array}$ \\
\hline 5. Maintenance of magnetospheric ions & Well explained & $\begin{array}{l}\text { Requires ion reflection off of magnetopause } \\
\text { Alfvén waves or a magnetic bottle } \\
\text { on open field lines }\end{array}$ \\
\hline $\begin{array}{l}\text { 6. Some weak loss of magnetospheric ions } \\
\text { in some events }\end{array}$ & Not explained & $\begin{array}{l}\text { Requires only a weakening of } \\
\text { the mechanism invoked for } 5 \text {. }\end{array}$ \\
\hline $\begin{array}{l}\text { 7. Low event phase velocity (and } \\
\text { similarly low field-perpendicular } \\
\text { plasma velocity within event) }\end{array}$ & Consistent & $\begin{array}{l}\text { Requires geometry such that tension force } \\
\text { and sheath flow are close to being in balance }\end{array}$ \\
\hline 8. Balanced counterstreaming electrons & $\begin{array}{l}\text { Requires identical electron acceleration in } \\
\text { both ionospheres (even if there is additional } \\
\text { heating at the magnetopause) }\end{array}$ & $\begin{array}{l}\text { Requires weak heating of entering sheath } \\
\text { electrons at magnetopause (which then } \\
\text { mirror at low altitudes) }\end{array}$ \\
\hline 9. Correspondence with IMF clock angle & Not explained & Well explained as reconnection pulses \\
\hline $\begin{array}{l}\text { 10. No correspondence with solar wind } \\
\text { pressure pulses }\end{array}$ & $\begin{array}{l}\text { Eliminates several suggested } \\
\text { mechanisms }\end{array}$ & Consistent \\
\hline 11. Ionospheric events & Not explained & Well explained as reconnection pulses \\
\hline
\end{tabular}

considerable distance down the tail and hence, sheath precipitation fluxes were low. The newer open field lines were seen as a region of higher sheath fluxes that were to the dusk side and not near noon. We can identify this patch of sheath plasma precipitation with one of the poleward-moving enhancements seen by the low elevation ESR beam.

Given that these events are well understood as transient plasma injections caused by bursts of reconnection, the one major surprise is that there was no bipolar deflection in the field seen by cluster, at least in most of the cases. This is the classic characteristic used to define FTEs. However, it is important to remember where these Cluster observations were made. Most of the events were seen on southward-pointing field lines, i.e. on the boundary of the interior magnetic cusp, half way between the magnetopause boundary layer and its projection at middle altitudes. Only the last events, for which the satellites were moving onto a northward pointing field, showed indications of bipolar FTE field signatures. Even in these cases, the bipolar signature was weak; however, we note that $B_{Z}$ was still close to zero and thus, the satellites were only just entering the exterior boundary layer. We conclude that the bipolar FTE signatures are a feature only of the exterior boundary layer. They are not seen on the southwardpointing field on the edges of the interior magnetic cusp (nor are they seen at middle altitudes).

The lack of a bipolar magnetic signature for the first event studied here (at around 11:23) is due to the fact that the event does not bulge out in response to increased pressure from within the event. The magnetic field magnitude (pressure) is of the order of $30 \mathrm{nT}(0.36 \mathrm{nPa})$ in the event centre and $24 \mathrm{nT}(0.23 \mathrm{nPa})$ outside of it. Thus the field pressure excess for this event is $1.3 \mathrm{nPa}$. Figure 9 shows that the ion concentration, parallel temperature and perpendicular temperatures at the event centre are of the of order $6.31 \times 10^{5} \mathrm{~m}^{-3}, 2.51 \times 10^{7} \mathrm{~K}$ and $3.16 \times 106 \mathrm{~K}$, respectively. The corresponding values outside the event are $2.00 \times 10^{5} \mathrm{~m}^{-3}, 6.31 \times 10^{7} \mathrm{~K}$ and $6.31 \times 10^{7} \mathrm{~K}$. These numbers yield a roughly isotropic ion pressure outside the event of $0.17 \mathrm{nPa}$, but field-perpendicular and field-parallel ion pressures of $0.03 \mathrm{~Pa}$ and $0.22 \mathrm{nPa}$ inside it. Thus, the drop in field-perpendicular ion pressure was $0.14 \mathrm{nPa}$ and there was a slight rise in the field-parallel ion pressure of $0.05 \mathrm{nPa}$. Full pressure balance considerations (including the electron gas) will be made elsewhere, but we note that the increased magnetic pressure in this event is comparable with the drop in the field-perpendicular ion pressure. Thus, these events are much closer to existing a pressure equilibrium than are the FTEs on the exterior boundary: with this being the case, a bipolar magnetic signature is not expected.

This can be contrasted with the event closer to the outer boundary around 12:50 (for which a bipolar magnetic FTE signature was seen). In this event, the field magnitude rose 
from 20 to $24 \mathrm{nT}$, giving a modest field pressure increase of $0.04 \mathrm{nPa}$. The ion concentration variation was similar to the 11:23 case, but the perpendicular temperature fell to only $3 \times 10^{7} \mathrm{~K}$, such that the field-perpendicular ion pressure rose from $0.17 \mathrm{nPa}$ outside the event to $0.25 \mathrm{nPa}$ inside it. Thus, both the magnetic and ion pressures show an excess in this event, which is consistent with the bipolar field signature and with FTE events on the exterior magnetopause boundary.

Acknowledgements. This paper is dedicated to the memory of three Cluster-1 PIs, Alan Johnstone, Les Wooliscroft and Berend Wilken who's tireless work, skill, enthusiasm is remembered by all who knew them. We thank R. Bonnet and all ESA staff who ensured Cluster finally made the first 3D measurements in space. The authors are also particularly grateful to Halvard Bohlm, who with APvE, managed to reach and run the ESR radar on 14 January 2001, despite very severe weather conditions on Svalbard. EISCAT is an Association of Seven member nations: France, Germany, Sweden, Norway, Finland, UK and Japan and the authors are grateful to the director and staff of EISCAT for the provision of the EISCAT research facilities. EISCAT, Cluster and CUTLASS are projects which are funded in the UK by the Particle Physics and Astronomy Research Council (PPARC) and MLo, AF, MAH, MNW, RS, MD, JAW, IWM, MT, AB, GP, SKM and MLe are grateful for PPARC support. The SuperDARN radars are supported by funds from the research agencies of Australia, Canada, Finland, France, Italy, Japan, Sweden, UK and the USA. Other authors also acknowledge support from national funding agencies: HJO, PE and FP by NFR, Sweden; JM by NF, Norway, MFM by PNRA, Italy; work by GL at HAO/NCAR was supported by the NASA SEC Guest Investigator program; work at CESR was funded by CNES grants. The MIRACLE network is operated as an international collaboration under the leadership of the Finnish Meteorological Institute. The IMAGE magnetometer data are collected as a Finnish-GermanNorwegian-Polish-Russian-Swedish project.

Topical Editor G. Chanteur thanks A. Nishida and another referee for their help in evaluating this paper.

\section{References}

Akasofu, S. I., Hones, Jr., E. W., Bame, S. J., Ashbridge, J. R., and Lui, A. T. Y.: Magnetotail and boundary layer plasma at geocentric distance of $18 R_{E}$, J. Geophys., Res., 78, 7257, 1973.

Alem, F. and Delcourt, D. C.: Nonadiabatic precipitation of ions at the cusp equatorward edge, J. Geophys. Res., 100, 19, 321, 1995.

Anderson, B. J., Phan, T. D., and Fuselier, S. A.: Relationships between plasma depletion and subsolar reconnection, J. Geophys. Res., 102, 9531-9542, 1997.

Aparicio, B., Thelin, B., and Lundin, R.: The polar cusp from a particle point of view: A statistical model based on Viking data, J. Geophys. Res., 14, 023, 1991.

Berchem, J. and Russell, C. T.: Flux transfer events on the magnetopause: Spatial distribution and controlling factors, J. Geophys. Res., 89, 6689-6703, 1984.

Bodokova, N. L., Zastenker, G. N., and Sibeck, D. G.: A case and statistical study of transient magnetic field events at geosynchronous orbit and their solar wind, J. Geophys. Res., 100, 56435656, 1995.

Boyle, C. B., Reiff, P. H., and Hairston, M. R.: Empirical polar cap potentials, J. Geophys. Res., 102, 111-125, 1997.
Burch, J. L.: Quasi-neutrality in the polar cusp, Geophys. Res. Lett., 12, 469-472, 1985.

Burch, J. L., Reiff, P. H., and Sugiura, M.: Upward electron beams measured by DE-1: a primary source of dayside region 1 Birkeland currents, Geophys. Res. Lett., 10, 753-756, 1983.

Chandler, M. O., Fuselier, S. A., Lockwood, M., and Moore, T. E.: Evidence of component magnetic merging equatorward of the cusp, J. Geophys. Res., 104, 22 623-22 648, 1999.

Collin, H. L., Sharp, R. D., and Shelley, E. G.: The occurrence and characteristics of electron beams over the polar regions, J. Geophys. Res., 87, 7504, 1982.

Cowley, S. W. H.: The causes of convection in the Earth's magnetosphere: A review of developments during IMS, Rev. Geophys., 20, 531-565, 1982.

Cowley, S. W. H.: Solar wind control of magnetospheric convection, in Achievements of the international magnetospheric study, IMS, pp 483-494, ESA SP-217, ESTEC, Noordwijk, The Netherlands, 1984.

Cowley, S. W. H. and Lewis, Z. V., Magnetic trapping of energetic particles on open dayside boundary layer flux tubes, Planet. Space Sci., 38, 1343, 1990.

Cowley, S. W. H., Freeman, M. P., Lockwood, M., and Smith, M. F.: The ionospheric signature of flux transfer events, in: "CLUSTER - dayside polar cusp", (Ed) Barron, C. I., ESA SP-330, European Space Agency Publications, Nordvijk, The Netherlands, 105-112, 1991.

Crooker, N. U.: Reverse convection, J. Geophys. Res., 97, 19363 19372, 1992.

Daly, P. W. and Fritz, T. A.: Trapped electron distributions on open field lines, J. Geophys. Res., 87, 6081, 1982.

Daly, P. W., Saunders, M. A., Rijnbeek, R. P., Sckopke, N., and Russell, C. T.: The distribution of reconnection geometry in flux transfer events using energetic ion, plasma, and magnetic data, J. Geophys. Res., 89, 3843, 1984.

Drakou, E., Sonnerup, B. U.Ö., and Lotko, W.: Self-consistent steady state model of the low-latitude boundary layer, J. Geophys. Res., 99, 2351-2364, 1994.

Eastman, T. E. and Hones, Jr., E. W., Characteristics of the magnetospheric boundary layer as observed by IMP-6, J. Geophys. Res., 84, 2109, 1979.

Eastman, T. E., Hones, Jr., E. W., Bame, S. J., and Ashbridge, J. R.: The magnetospheric boundary layer: Site of plasma, momentum and energy transfer from the magnetosheath to the magnetosphere, Geophys. Res. Lett., 3, 685-688, 1976.

Elphic, R. C.: Observations of flux transfer events: Are FTEs flux ropes, islands, or surface waves?, in: Physics of Magnetic Flux Ropes, Geophys. Monogr. Ser., vol. 58, (Eds) Russell, C. T., Preist, E. R., and Lee, L. C., AGU, Washington, D. C., pp. 455472, 1990.

Elphic, R. C. and Southwood, D. J.: Simultaneous measurements of the magnetopause and flux transfer events at widely separated sites by AMPTE UKS and ISEE 1 and 2, J. Geophys. Res., 92, 13, 666-672, 1987.

Elphic, R. C., Lockwood, M., Cowley, S. W. H., and Sandholt, P. E.: Signatures of flux transfer events at the dayside magnetopause and in the ionosphere: Combined ISEE, EISCAT and optical observations, Geophys. Res. Lett., 17, 2241-2244, 1990.

Elphic, R. C., Baumjohann, W., Cattell, C. A., Lühr, H., and Smith, M. F.: A search for upstream pressure pulses associated with flux transfer events: An AMPTE/ISEE case study, J. Geophys. Res., 99, 13, 521-527, 1994

Farrugia, C. J., et al.: A multi-instrument study of flux transfer event 
structure, J. Geophys. Res., 93, 14 465-14 477, 1988.

Fedorov, A., Budnik, E., Novrachev, M., Romanov, V., Song, P., and Sauvaud, J.-A.: Plasma characteristics near the exterior cusp under different orientations of the interplanetary magnetic field, Czech J. Phys., 49, 711-732, 1999.

Freeman, M. P., Farrugia, C. J., Burlaga, L. F., Hairston, M. R., Greenspan, M. E., Ruohoniemi, J. M., and Lepping, R. P.: The interaction of a magnetic cloud with the earth: ionospheric convection in the northern and southern hemispheres for a wide range of quasi-steady interplanetary magnetic field conditions, J. Geophys. Res., 98, 7633-7655, 1993.

Fujimoto, M., Terasawa, T., Mukai, T., Saito, Y., Yamamoto, T., and Kokubun, S.: Plasma entry into the flanks of the near-Earth magnetotail: Geotail observations, J. Geophys. Res., 103, 43914408, 1998.

Fuselier, S. A., Klumpar, D. M., and Shelley, E. G.: Ion reflection and transmission during reconnection at the Earth's subsolar magnetopause, Geophys. Res. Lett., 18, 139, 1991.

Fuselier, S. A., Klumpar, D. M., and Shelley, E. G.: Counterstreaming magnetosheath ions in the dayside low latitude boundary layer, Geophys. Res. Lett., 19, 425-428, 1992.

Fuselier, S., Anderson, B. J., and Onsager, T.G.: Electron and ion signatures of field line topology at the low shear magnetopause, J. Geophys. Res., 100, 11 805-11 814, 1995.

Fuselier, S. A., Lockwood, M., Onsager, T. G., and Peterson, W. K.: The source population for the cusp and cleft/LLBL for southward IMF, Geophys. Res. Lett., 26, 1665-1669, 1999.

Galeev, A. A., Kuznetsova, M. M., and Zeleny, L. M.: Magnetopause stability threshold for patchy reconnection, Space Sci Rev., 44, 1-41, 1986.

Gosling, J. T., Thomsen, M. F., Bame, S. J., Elphic, R. C., and Russell, C. T.: Plasma flow reversals at the dayside magnetopause and the origin of asymmetric polar cap convection, J. Geophys. Res., 95, 8073-8084, 1990a.

Gosling, J. T., Thomsen, M. F., Bame, S. J., Elphic, R. C., and Russell, C. T.: Cold ion beams in the low-latitude boundary layer during accelerated flow events, Geophys. Res. Lett., 17, 22452248, 1990b.

Gosling, J. T., Thomsen, M. F., Bame, S. J., Onsager, T. G., and Russell, C. T.: The electron edge of the low-latitude boundary layer during accelerated flow events, Geophys. Res. Lett., 17, 1833-1836, 1990c.

Gosling, J. T., Thomsen, M. F., Bame, S. J., Elphic, R. C., and Russell, C. T.: Observations of reconnection of interplanetary and lobe magnetic field lines at the latitude magnetopause, J. Geophys. Res., 96, 14 097-14 106, 1991.

Haerendel, G., Paschmann, G., Sckopke, N., Rosenbauer, H., and Hedgecock, P. C.: The frontside boundary layer of the magnetopause and the problem of reconnection, J. Geophys. Res., 83, 3195-3216, 1978.

Hall, D. S., Chanelor, C. P., Bryant, D. A., Lepine, D. R., and Tritakis, V. P.: Electrons in the boundary layers near the dayside magnetopause, J. Geophys. Res., 96, 7869, 1991.

Hapgood, M. A. and Bryant, D. A.: Re-ordered electron data in the low-latitude boundary layer, Geophys. Res. Lett. 17, 2043-2046, 1990.

Hapgood, M. A. and Bryant, D. A.: Exploring the magnetospheric boundary layer, Planet. Space Sci., 40, 1431-1459, 1992.

Hapgood, M. A. and Lockwood, M.; On the voltage and distance across the low latitude boundary layer, Geophys. Res. Lett., 20, 145-148, 1993.

Hapgood, M. A. and Lockwood, M.: Rapid changes in LLBL thick- ness, Geophys. Res. Lett., 22, 77-80, 1995.

Heelis, R. A., Hanson, W. B., and Burch, J. L.: Ion convection reversals in the dayside cleft, J. Geophys. Res., 81, 3803, 1976.

Heyn, M. F., Biernat, H. K., Rijnbeek, R. P., and Semenov, V. S.: The structure of reconnection layers, J. Plasma Phys., 40, 2, 235252, 1988.

Hill, T. W. and Reiff, P. H.: Evidence of magnetospheric cusp proton acceleration by magnetic merging at the dayside magnetopause, J. Geophys. Res., 82, 3623, 1977.

Hones, Jr., E. W., Ashbridge, J. R., Bame, S. J., Montgomery, M. D., Singer, S., and Akasofu, S.-I.: Measurements of magnetotail plasma flow made with Vela 4B, J. Geophys. Res., 77, 5503, 1972.

Johnstone, A. D., Rodgers, D. J., Coates, A. J., Smith, M. F., and Southwood, D. J.: Ion acceleration during steady-state reconnection at the dayside magnetopause, in: Ion acceleration in the magnetosphere and ionosphere, (Ed) Chang, T., AGU Monograph 38, 136-145, 1986.

Jørgensen, T. S., Friis-Christiansen, E., Wickwar, V. B., Kelly, J. D., Clauer, C. R., and Banks, P. M.: On the reversal from "sunward" to "antisunward" plasma convection in the dayside high latitude ionosphere, Geophys. Res. Lett., I, 887-890, 1984.

Karlson, K. A., Øieroset, M., Moen, J., and Sandholt, P. E.: A statistical study of flux transfer event signatures in the dayside aurora: the IMF By-related postnoon-prenoon asymmetry, J Geophys. Res., 101, 59-68, 1996.

Kawano, H. and Russell, C. T., Survey of flux transfer events observed with the ISEE spacecraft: rotational polarity and the source region, J. Geophys. Res., 101, 27 299-27 308, 1996.

Kawano, H. and Russell, C. T., Survey of flux transfer events observed with the ISEE spacecraft: dependence on the interplanetary magnetic field, J. Geophys. Res., 102, 11 307-11 313, 1997.

Kawano, H., Kokubun, S., and Takahashi, K.: Survey of transient magnetic field events in the dayside magnetosphere, J. Geophys. Res., 97, 10, 677-692, 1992.

Klumpar, D. M. and Heikkila, W. J.: Electrons in the ionospheric source cone: evidence for runaway electrons as carriers of downward Birkeland currents, Geophys. Res. Lett., 9, 873, 1992.

Kremser, G., Woch, J., Mursala, K., Tanskanen, P., Wilken, B., and Lundin, R.: Origin of energetic ions in the polar cusp inferred from ion composition measurements by the Viking satellite, Ann. Geophysicae, 13, 595-607, 1995.

Kuo, H., Russell, C. T., and Le, G.: Statistical studies of flux transfer events, J. Geophys. Res., 100, 3513-3519, 1995.

Levy, R., Petschek, H. E., and Siscoe, G. L.: Aerodynamic aspects of magnetospheric flow, AIAA J., 2, 2065, 1964.

Lin, Y. and Lee, L. C.: The structure of reconnection layers in the magnetosphere, Space Sci. Rev., 65, 59-179, 1993.

Lockwood, M.: Flux transfer events at the dayside magnetopause: Transient reconnection or magnetosheath pressure pulses?, J. Geophys. Res., 96, 5497-5509, 1991.

Lockwood, M.: Ionospheric signatures of pulsed magnetopause reconnection, in: "Physical signatures of magnetopause boundary layer Processes", (Eds) Holtet, J. A. and Egeland, A., NATO ASI Series C, Vol. 425, Kluwer, 229-243, 1994.

Lockwood, M.: The location and characteristics of the reconnection X-line deduced from low-altitude satellite and ground-based observations, 1, Theory, J. Geophys. Res., 100, 21, 791, 1995.

Lockwood, M.: The relationship of dayside auroral precipitations to the open-closed separatrix and the pattern of convective flow, J. Geophys. Res., 102, 17475-17487, 1997a.

Lockwood, M.: Energy and pitch angle dispersions of LLBL/cusp 
ions seen at middle altitudes: predictions by the open magnetosphere model, Ann. Geophysicae, 15, 1501-1511, 1997b.

Lockwood, M. and Davis, C. J.: On the longitudinal extent of magnetopause reconnection bursts, Ann. Geophysicae, 14, 865-878, 1996.

Lockwood, M. and Hapgood, M. A.: How the Magnetopause Transition Parameter Works, Geophys. Res. Lett., 24, 373-376, 1997.

Lockwood, M. and Hapgood, M. A.: On the Cause of a Magnetospheric Flux Transfer Event, Geophys. Res., 103, 26 453-26478, 1998.

Lockwood, M. and Moen, J.: Ion populations on open field lines within the low-latitude boundary layer: theory and observations during a dayside transient event, Geophys. Res. Lett., 23, 28952898, 1996.

Lockwood, M. and Moen, J.: Reconfiguration and closure of lobe flux by reconnection during northward IMF: evidence for signatures in cusp/cleft auroral emissions, Ann. Geophysicae, 17, 996-1011, 1999.

Lockwood, M. and Smith, M. F.: The variation of reconnection rate at the dayside magnetopause and cusp ion precipitation, J. Geophys. Res., 97, 14, 841, 1992.

Lockwood, M. and Smith, M. F.: Comment on "Mapping the dayside ionosphere to the magnetosphere according to particle precipitation characteristics" by Newell and Meng, Geophys. Res. Lett., 20, 1739-1740, 1993.

Lockwood, M. and Smith, M. F.: Low and middle-altitude cusp particle signatures for general magnetopause reconnection rate variations, I, Theory, J. Geophys. Res., 99, 8531, 1994.

Lockwood, M., Moen, J., Cowley, S. W. H., Farmer, A. D., Løvhaug, U. P., Lühr, H., and Davda, V. N.: Variability of dayside convection and motions of the cusp/cleft aurora, Geophys. Res. Lett., 20, 1011-1014, 1993.

Lockwood, M., Onsager, T. G., Davis, C. J., Smith, M. F., and Denig, W. F.: The characteristics of the magnetopause reconnection X-line deduced from low-altitude satellite observations of cusp ions, Geophys. Res. Lett., 21, 2757-2760, 1994.

Lockwood, M., Cowley, S. W. H., Smith, M. F., Rijnbeek, R. P., and Elphic, R. C.: The contribution of flux transfer events to convection, Geophys. Res. Lett., 22, 1185-1188, 1995.

Lockwood, M., Cowley, S. W. H., and Onsager, T. G.: Ion acceleration at both the interior and exterior Alfvén waves associated with the magnetopause reconnection site: signatures in cusp precipitation, J. Geophys. Res., 101, 21, 501, 1996.

Lockwood, M., Davis, C. J., Onsager, T. G., and Scudder, J. A.: Modelling signatures of pulsed magnetopause reconnection in cusp ion dispersion signatures seen at middle altitudes, Geophys. Res. Lett., 25, 591-594, 1998.

Lockwood, M., Opgenoorth, H., van Eyken, A. P., Fazakerley, A., Bosqued, J.-M., Denig, W., Wild, J., Cully, C., Greenwald, R., Lu, G., Amm, O., Frey, H., Strømme, A., Prikryl, P., Hapgood, M. A., Wild, M. N., Stamper, R., Taylor, M., McCrea, I., Kauristie, K., Pulkkinen, T., Pitout, F., Balogh, A., Dunlop, M., Rème, H., Behlke, R., Hansen, T., Provan, G., Eglitis, P., Morley, S. K., Alcaydé, D., Blelly, P.-L., Moen, J., Donovan, E., Engebretson, M., Lester, M., Waterman, J., and Marcucci, M. F.: Coordinated Cluster, ground-based instrumentation and low-altitude satellite observations of transient poleward-moving events in the ionosphere and in the tail lobe, Ann. Geophysicae, this issue, 2001.

Lotko, W. and Sonnerup, B. U. Ø.: The low-latitude boundary layer on closed field lines, in: Physics of the Magnetopause, Geophys. Monogr. Ser., vol. 90, (Eds) Song, P., Sonnerup, B. U. Ø., and
Thomsen, M., AGU Washington, D. C., pp. 371-383, 1995.

Lu, G., Richmond, A. D., Emery, B. A., Reiff, P. H., de la Beaujardiere, O., Rich, F. J., Denig, W. F., Kroehl, H. W., Lyons, L. R., Ruohoniemi, J. M., Friis-Christensen, E., Opgenoorth, H., Persson, M. A. L., Lepping, R. P., Rodger, A. S., Hughes, T., McEwin, A., Dennis, S., Morris, R., Burns, G., and Tomlinson, L.: Interhemispheric asymmetry of the high-latitude ionospheric convection pattern, J. Geophys. Res., 99, 6491-6510, 1994.

Lyons, L. R., Schulz, M., Pridmore-Brown, D. C., and Roeder, J. L.: Low-latitude boundary layer near noon: An open field line, J. Geophys. Res., 99, 2227, 1994.

Manuel, J. R. and Samson, J. C.: The spatial development of the low-latitude boundary layer, J. Geophys. Res., 98, 17, 367-385, 1993.

McCrea, I. W., Lockwood, M., Moen, J., Pitout, F., Eglitis, P., and Aylward, A. D.: ESR and EISCAT observations of the response of the cusp and cleft to IMF orientation changes, Ann. Geophysicae, 18, 1009-1026, 2000.

McWilliams, K. A., Yeoman, T. K., and Provan, G.: A statistical survey of dayside pulsed ionospheric flows as seen by the CUTLASS Finland HF radar, Ann. Geophysicae, 18, 445-453, 2000.

McWilliams, K. A., Yeoman, T. K., and Cowley, S. W. H.: Twodimensional electric field measurement in the ionospheric footprint of a flux transfer event, 18, Ann. Geophysicae, 1584-1598, 2001.

Milan, S. E., Lester, M., Cowley, S. W. H., and Brittnacher, M.: Convection and auroral response to a southward turning of the IMF: Polar UVI, CUTLASS and IMAGE signatures of transient magnetic flux transfer at the magnetopause, J. Geophys. Res., 105, 15, 741-757, 2000.

Mitchell, D. G., Kutchko, F., Williams, D. J., Eastman, T. E., Frank, L. A., and Russell, C. T.: An extended study of the low-latitude boundary layer on the dawn and the dusk flanks on the magnetosphere, J. Geophys. Res., 92, 7394, 1987.

Moen, J., Evans, D., Carlson, H. C., and Lockwood, M.: Dayside moving auroral transients related to LLBL dynamics, Geophys. Res. Lett., 23, 3247-3250, 1996.

Mozer, F. S., Hayakawa, H., Kokubun, S., Nakamura, M., Okada, T., Yamamoto, T., and Truruda, K.: The morningside lowlatitude boundary layer as determined from electric and magnetic field measurements on Geotail, Geophys. Res. Lett., 21, 29832986, 1994.

Neudegg, D. A., Yeoman, T. K., Cowley, S. W. H., Provan, G., Haerendel, G., Baumjohann, W., Auster, U., Fornacon, K.-H., Georgescu, E., and Owen, C. J., A flux transfer event observed at the magnetopause by the equator-S spacecraft and in the ionosphere by the CUTLASS HF radar, Ann. Geophysicae, 17, 707711, 1999.

Newell, P. T. and Meng, C.-I.: The cusp and the cleft/LLBL: Low altitude identification and statistical local time variation, J. Geophys. Res., 93, 14, 549, 1988.

Newell, P. T. and Meng, C.-I.: On quantifying the distinctions between the cusp and the cleft/LLBL, in: Electromagnetic coupling in the polar clefts and caps NATO ASI Ser C, vol. 278, (Eds) Sandholt, P. E. and Egeland, A., Kluwer Academic Publishers, Dordrecht, pp. 87-101, 1989.

Newell, P. T. and Meng, C.-I.: Mapping the dayside ionosphere to the magnetosphere according to particle precipitation characteristics, Geophys. Res. Lett., 19, 609-612, 1992.

Newell, P. T. and Meng, C.-I.: Reply, Geophys. Res. Lett., 20, 1741-1742, 1993.

Newell, P. T. and Meng, C.-I.: Ionospheric projections of magne- 
tospheric regions under low and high solar wind pressure conditions, J. Geophys. Res., 99, 273, 1994a.

Newell, P. T. and Meng, C.-I.: Comment on "Unexpected features of the ion precipitation in the so-called cleft/low latitude boundary layer region: Association with sunward convection and occurrence on open field lines" by Nishida, A., Mukai, T., Hayakawa, H., Matsuoka, A., Tsuruda, K., Kaya, N., and Fukunishi, H., J. Geophys. Res., 99, 19, 609, 1994b.

Newell, P. T. and Meng, C.-I.: Open and closed low-latitude boundary layer, in: "Polar Cap Boundary Phenomena", (Eds) Moen, J., Egeland, A., and Lockwood, M., NATO ASI Series C, Kluwer, 1997.

Newell, P. T., Burke, W. J., Sanchez, E. R., Meng, C.-I., Greenspan, M. E., and Clauer, C. R.: The low-latitude boundary and the boundary plasma sheet at low altitude: Prenoon precipitation regions and convection reversal boundaries, J. Geophys. Res., 96, 21, 013, 1991.

Nishida, A.: Can random reconnection on the magnetopause produce the low-latitude boundary layer?, Geophys. Res. Lett., 16, 227-230, 1989.

Nishida, A. and Mukai, T.: Reply to comment on "Unexpected features of the ion precipitation in the so-called cleft/low-latitude boundary layer region" by Nishida, A., et al., J. Geophys. Res., 99, 23, 367, 1994.

Nishida, A., Mukai, T., Hayakawa, H., Matsuoka, A., and Tsuruda, K.: Unexpected features of the ion precipitation in the so-called cleft/low-latitude boundary layer region: Association with sunward convection and occurrence on open field lines, J. Geophys. Res., 98, 11, 161, 1993.

Nishida, A., Mukai, T., Yamamoto, T., Kokubun, S., and Maezawa, K.: A Unified model of the magnetotail convection in geomagnetically quiet and active times, J. Geophys. Res., 103, 44094418, 1998.

Ogilvie, K., Fitzenreiter, R. J., and Scudder, J. D.: Observations of electron beams in the low-latitude boundary layer, J. Geophys. Res., 89, $10723,1984$.

Onsager, T. G.: A quantitative model of magnetosheath plasma in the low-latitude boundary layer, cusp and mantle, in: "Physical signatures of magnetopause boundary layer Processes", (Eds) Holtet, J. A. and Egeland, A. NATO ASI Series C, Vol. 425, Kluwer, pp. 385-400, 1994.

Onsager, T. G. and Fuselier, S. A.: The location of the magnetopause reconnection for northward and southward interplanetary magnetic field, in: Solar System Plasmas in Space and Time, Geophys. Mono. Ser., vol. 84, (Eds) Burch, J. L. and Waite, Jr., J. H., AGU, Washington D. C., pp. 183-197, 1994.

Onsager, T. G., Scudder, J. D., and Lockwood, M.: High-latitude particle precipitation and its relationship to magnetospheric source regions, Space Sci. Rev., 80, 77-107, 1997.

Onsager, T. G., Kletzing, C. A., Austin, J. B., and MacKiernan, H.: Model of magnetosheath plasma in the magnetosphere: Cusp and mantle precipitations at low altitudes, Geophys. Res. Lett., 20, 479-482, 1993.

Opgennoorth, H. J., Lockwood, M., Alcaydé, D., et al., coordinated ground-based, low altitude satellite and Cluster observations on global and local scales, during a transient postnoon sector excursion of the magnetospheric cusp, Ann. Geophysicae, this issue, 2001.

Owen, C. J. and Cowley, S. W. H.: Heikkila's mechanism for impulsive plasma transport through the magnetopause: A reexamination, J. Geophys. Res., 96, 5565-5574, 1991.

Owen, C. J. and Slavin, J. A.: Viscously driven plasma flows in the deep geomagnetic tail, Geophys. Res. Lett., 19, 1443-1446, 1992.

Paschmann, G., Sonnerup, B. U. Ö., Papamastorakis, I., Sckopke, N., Haerendel, G., Bame, S. J., Asbridge, J. R., Gosling, J. T., Russell, C. T., and Elphic, R. C.: Plasma acceleration at the Earth's magnetopause: Evidence for reconnection, Nature, 282, 243-246, 1979.

Paschmann, G., Papamastorakis, I., Baumjohann, W., Sckopke, N., Carlson, C. W., Sonnerup, B. U. Ö., and Lühr, H.: The magnetopause for large magnetic shear: AMPTE/IRM observations, J. Geophys. Res., 91, 11 099-11 115, 1986.

Paschmann, G., Sonnerup, B. U. Ö., Papamastorakis, I., Baumjohann, W., Sckopke, N., and Lühr, H.: The magnetopause and boundary layer for small magnetic shear: convection electric fields and reconnection, Geophys. Res. Lett., 17, 1829-1832, 1990.

Phan, T. D., et al.: Low-latitude flank magnetosheath, magnetopause and boundary layer for low magnetic shear: Wind observations, J. Geophys. Res., 102, 19, 883-895, 1997.

Reiff, P. H. and Luhmann, J. G.: Solar wind control of the polar cap voltage, in: "Solar Wind-Magnetosphere Coupling”, (Eds) Kamide, Y. and Slavin, J. A., Terra Scientifica, Tokyo, p. 453, 1986.

Reiff, P. H., Hill, T. W., and Burch, J. L.: Solar wind plasma injection at the dayside magnetospheric cusp, J. Geophys. Res., 82, 479, 1977.

Richard, R. L., Walker, R. J., and Ashour-Abdalla, M.: The population of the magnetosphere by solar wind ions when the interplanetary magnetic field is northward, Geophys. Res. Lett., 21, 2455-2458, 1994.

Rijnbeek, R. P., Cowley, S. W. H., Southwood, D. J., and Russell, C. T.: A survey of dayside flux transfer events observed by the ISEE 1 and 2 magnetometers, J. Geophys. Res., 89, 786-800, 1984.

Rijnbeek, R. P., Farrugia, C. J., Southwood, D. J., Dunlop, M. W., Mier-Jedrejowicz, W. A. C., Chaloner, C. P., Hall, D. S., and Smith, M. F.: A magnetic boundary signature within flux transfer events, Planet. Space Sci., 35, 871-878, 1987.

Rosenbauer, H., Grünwaldt, H., Montgomery, M. D., Paschmann, G., and Sckopke, N.: HEOS 2 plasma observations in the distant polar magnetosphere: The plasma mantle, J. Geophys. Res., 80, 2723-2737, 1975.

Ruohoniemi, J. M., Greenwald, R. A., Baker, K. B., Villain, J.-P., Hanuise, C., and Kelley, J. D.: Mapping high latitude plasma convection with coherent HF radars, J. Geophys. Res., 94, 13 463, 1989.

Russell, C. T. and Elphic, R. C.: Initial ISEE magnetometer results: Magnetopause observations, Space Sci. Rev., 22, 681-715, 1978.

Russell, C. T. and Elphic, R. C.: ISEE observations of flux transfer events at the dayside magnetopause, Geophys. Res. Lett., 6, 3336, 1979.

Sandholt, P. E., Farrugia, C. J., Øieroset, M., Stauning, P., and Cowley, S. W. H.: Auroral signature of lobe reconnection, Geophys. Res. Lett., 23, 1725-1728, 1996.

Sandholt, P. E., Farrugia, C. J., Moen, J., and Lybekk, B.: The dayside aurora and its regulation by the interplanetary magnetic field, in: "Polar Cap Boundary Phenomena", (Eds) Moen, J., Egeland, A., and Lockwood, M., NATO ASI Series C, Vol. 509, Kluwer, Dordrecht, pp. 189-208, 1998.

Sandholt, P. E., Farrugia, C. J., Moen, J., and Cowley, S. W. H.: Dayside auroral configurations: responses to southward and northward rotations of the interplanetary magnetic field, J. Geophys. Res., in press, 1999. 
Sanny, J., Sibeck, D. G., Venturini, C. C., and Russell, C. T.: A statistical study of transient events in the outer dayside magnetosphere, J. Geophys. Res., 101, 4939-4952, 1996.

Saunders, M. A.: Recent ISEE observations of the magnetopause and low-latitude boundary layer: A review, J. Geophys., 52, 190198, 1983.

Saunders, M. A., Russell, C. T., and Sckopke, N.: A dual-satellite study of spatial properties of FTEs, in: Magnetic Reconnection in Space and Laboratory Plasmas, Geophys. Monogr. Ser., vol. 30, (Ed) Hones, Jr., E. W., AGU, Washington, D. C., pp. 145152, 1984a.

Saunders, M. A., Russell, C. T., and Sckopke, N.: Flux transfer events, scale size and interior structure, Geophys. Res. Lett., 11, 131-134, 1984b.

Savin, S. P., Balan, O., Borodkova, N., Budnik, E., Nikolaeva, N., Prokhorenko, V., Pulkkinen, T., Rybjeva, N., Safrankova, J., Sandahl, I., Amata, E., Auster, U., Bellucci, G., Blagau, A., Blecki, J., Buechner, J., Ciobanu, M., Dubinin, E., Yermolaev, Yu., Echim, M., Fedorov, A., Formisano, V., Grard, R., Ivchenko, V., Jiricek, F., Juchniewicz, J., Klimov, S., Korepanov, V., Koskinen, H., Kudela, K., Lundin, R., Lutsenko, V., Marghitu, O., Nemecek, Z., Nikutowski, B., Nozdrachev, M., Orsini, S., Parrot, M., Petrukovich, A., Pissarenko, N., Romanov, S., Rauch, J., Rustenbach, J., Sauvaud, J. A., Sarris, E. T., Skalsky, A., Smilauer, J., Triska, P., Trotignon, J. G., Vojta, J., Zastenker, G., Zelenyi, L., Agafonov, Yu., Grushin, V., Khrapchenkov, V., Prech, L., and Santolik, O.: Interball Magnetotail boundary case studies, Adv. Space Res., 20, 4/5, 999-1015, 1997.

Scholer, M.: Magnetic flux transfer at the magnetopause based on single $X$-line bursty reconnection, Geophys. Res. Lett., 15, 291294, 1988a.

Scholer, M.: Strong core magnetic fields in magnetopause flux transfer events, Geophys. Res. Lett., 15, 748-751, 1988 b.

Scholer, M.: Asymmetric time-dependent and stationary magnetic reconnection at the dayside magnetopause, J. Geophys. Res., 94, 15, 099-111, 1989.

Scholer, M., Daly, P. W., Paschmann, G., and Fritz, T. A.: Field line topology determined by energetic particles during a possible magnetopause reconnection event, J. Geophys. Res., 87, 6073, 1982a.

Scholer, M., Hovestadt, D., Ipavich, F. M., and Gloeckler, G.: Energetic protons, alpha particles and electrons in magnetic flux transfer events, J. Geophys. Res., 87, 2169, 1982 b.

Semenov, V. S., Kubyshkin, I. V., Biernat, H. K., Heyn, M. F., Rijnbeek, R. P., Besser, B. P., and Farrugia, C. J.: Flux transfer events interpreted in terms of a generalized model for Petschek-type reconnection, Adv. Space Res., 11, 9, 25-28, 1991.

Semenov, V. S., Lebedeva, V. V., Biernat, H. K., Heyn, M. F., Rijnbeek, R. P., and Farrugia, C. J.: Time-varying reconnection: Implications for magnetopause reconnection, J. Geophys. Res., 100, 21, 779-789, 1995.

Sharp, R. D., Shelley, E. G., Johnstone, R. G., and Ghielmetti, A. G.: Counter-streaming electron beams at $\sim 1 R_{E}$ over the auroral zone, J. Geophys. Res., 85, 92, 1980.

Shue, J.-H., Chao, J. K., Fu, H. C., Russell, C. T., Song, P., Kurana, K. K., and Singer, H. J.: A new functional form to study the solar wind control of the magnetopause size and shape, J. Geophys. Res., 102, 9497, 1997.

Sibeck, D. G.: A model for the transient magnetospheric response to sudden solar wind dynamic pressure variations, J. Geophys. Res., 95, 3755-3771, 1990.

Sibeck, D. G.: Transient events in the outer magnetosphere: Bound- ary waves or flux transfer events?, J. Geophys. Res., 97, 40094026, 1992.

Sibeck, D. G. and Newell, P. T.: Pressure-pulse driven surface waves at the magnetopause: a rebuttal, J. Geophys. Res., 100, 21, 773-778, 1995.

Sibeck, D. G., Paschmann, G., Treumann, R. A., Fuselier, S. A., Lennartsson, W., Lockwood, M., Lundin, R., Ogilvie, K. W., Onsager, T. G., Phan, T.-D., Roth, M., Scholer, M., Sckopke, N., Stasiewicz, K., and Yamauchi, M.: Plasma transfer processes at the magnetopause, Space Science Reviews, 88, 207-283, 1999.

Sckopke, N.: Plasma structure near the low-latitude boundary layer: a rebuttal, J. Geophys. Res., 96, 9815-9820, 1991.

Sckopke, N., Paschmann, G., Haerendel, G., Sonnerup, B. U. Ö., Bame, S. J., Forbes, T. G., Hones, Jr., E. W., and Russell, C. T.: Structure of the low-latitude boundary layer, J. Geophys. Res., 86, 2099-2110, 1981.

Smith, M. F. and Rodgers, D. J.: Ion distributions at the dayside magnetopause, J. Geophys. Res., 95, 11 617-11 624, 1991.

Smith, M. F. and Owen, C. J.: Temperature anisotropies in a magnetospheric FTE, Geophys. Res. Lett., 19, 1907-1910, 1992.

Song, P. and Russell, C. T.: Model of the formation of the lowlatitude boundary layer for strongly northward interplanetary magnetic field, J. Geophys. Res., 97, 1411, 1992.

Song, P., Elphic, R. C., Russell, C. T., Gosling, J. T., and Cattell, C. A.: Structure and properties of the subsolar magnetopause for northward IMF: ISEE observations, J. Geophys. Res., 95, 6375, 1990.

Song, P., Le, G., and Russell, C. T.: Observational differences between flux transfer events and surface waves at the magnetopause, J. Geophys. Res., 99, 2309-2320, 1994.

Song, P., Holzer, T. E., Russell, C. T., and Wang, Z.: Modelling the low-latitude boundary layer with reconnection entry, Geophys. Res. Lett., 21, 625-628, 1994.

Sonnerup, B. U. Ö.: Theory of the low-latitude boundary layer, J. Geophys. Res., 85, 2017, 1980.

Sonnerup, B. U. Ö., Paschmann, G., Papamastorakis, I., Sckopke, N., Haerendel, G., Bame, S. J., Ashbridge, J. R., Gosling, J. T., and Russell, C. T.: Evidence for magnetic field reconnection at the Earth's magnetopause, J. Geophys. Res., 86, 10 049-10067, 1981.

Sonnerup, B. U. Ö., Papamastorakis, I., Paschmann, G., and Lühr, H.: The magnetopause for large magnetic shear: analysis of convection electric fields from AMPTE/IRM, J. Geophys. Res., 95, 10 541-10 557, 1986.

Southwood, D. J., Saunders, M. A., Dunlop, M. W., MierJedrzejowicz, W. A. C., and Rijnbeek, R. P.: A survey of flux transfer events recorded by UKS spacecraft magnetometer, Planet. Space Sci., 34, 1349-1359, 1986.

Southwood, D. J., Farrugia, C. J., and Saunders, M. A.: What are flux transfer events?, Planet. Space Sci., 36, 503-508, 1988.

Spreiter, J. R., Summers, A. L., and Alksne, A. Y.: Hydromagnetic flow around the magnetosphere, Planet. Space Sci., 14, 223-253, 1966.

Takahashi, K., Sibeck, D. G., Newell, P. T., and Spence, H. E.: ULF waves in the low-latitude boundary layer and their relationship with magnetospheric pulsations: a multi-satellite observation, J. Geophys. Res., 96, 9503-9519, 1991.

Thompsen, M., Stansberry, J. A., Barne, S. J., Fuselier, S. A., and Gosling, J. T.: Ion and electron velocity distributions within flux transfer events, J. Geophys. Res., 92, 12, 127, 1987.

Traver, D. P., Mitchell, D. G., Williams, D. J., Frank, L. A., and Huang, C. Y.: Two encounters with the flank low-latitude bound- 
ary layer: further evidence for closed field topology and investigation of the internal structure, J. Geophys. Res., 96, 21, 025035, 1991.

Treumann, R. A., La Belle, J., and Pottelette, R.: Plasma diffusion at the magnetopause: the case of lower hybrid drift waves, J. Geophys. Res., 96, 16009-16013, 1991.

Treumann, R. A., LaBelle, J., and Bauer, T. M.: Diffusion processes: an observational perspective, in: Physics of the magnetopause, Geophys. Mono. 90, (Eds) Song, P., Sonnerup, B. U.Ö., and Thompsen, M., pp. 331-341, 1995.

Vasyliunas, V. M.: Interaction between the magnetospheric boundary layers and the ionosphere, in: Proceedings of the Magnetospheric Boundary Layers Conference, Alpbach, Eur. Space Agency Spec Publ., ESA SP-148, 387-394, 1979.

Williams, D. J., Mitchell, D. G., Eastman, T. E., and Frank, L. A.: Energetic particle observations in the low-latitude boundary layer, J. Geophys. Res., 92, 5097, 1978.

Wild, J. A., Cowley, S. W. H., Davies, J. A., Khan, H., Lester, M., Milan, S. E., Provan, G., Yeoman, T. K., Balogh, A., Dunlop, M. W., Fornacon, K.-H., and Georgescu, E.: First simultaneous oberservations of flux transfer events at the high-latitude magnetopause by the Cluster spacecraft and pulsed radar signatures in the conjugate ionosphere by the CUTLASS and EISCAT radars, Ann. Geophysicae, this issue, 2001.

Wilken, B., Daly, P. W., Mall, U., et al., First results from the RAPID Imaging Energetic Particle Spectrometer, Ann. Geophys- icae, this issue, 2001.

Wing, S., Newell, P. T., and Onsager, T. G.: Modelling the entry of the magnetosheath electrons into the dayside ionosphere, J. Geophys. Res., 101, 13 155-13 168, 1996.

Winske, D., Thomas, V. A., and Omidi, N.: Diffusion at the magnetopause: A theoretical perspective, in: Physics of the Magnetopause, Geophys. Monogr Ser., vol. 90, (Eds) Song, P., Sonnerup, B. U. Ö., and Thomsen, M. F., AGU, Washington, D.C., pp. 321-330, 1995.

Woch, J. and Lundin, R.: The low-latitude boundary layer at midaltitudes: Identification based on Viking hot plasma data, Geophys. Res. Lett., 20, 979-982, 1993.

Woch, J., Yamauchi, M., Lundin, R., Potemra, T. A., and Zanetti, L. J.: The low-latitude boundary layer at mid-altitudes: relation to large-scale Birkeland currents, Geophys. Res. Lett., 20, 22512254, 1993.

Woch, J., Lundin, R., Potemra, T. E., and Shapshak, M.: The projection of the magnetospheric boundary layers to mid-altitudes, (Eds) Holtet, J. A. and Egeland, A., Physical Signatures of Magnetospheric Boundary Layer Processes, Kluwer, pp. 83-97, 1994.

Xu, D., Kivelson, M. G., Walker, R. J., Newell, P. T., and Meng, C.-I.: Interplanetary magnetic field control of mantle precipitation and associated field-aligned currents, J. Geophys. Res., 100, 1837-1846, 1995. 